\title{
Single-particle measurements of bouncing particles and in situ collection efficiency from an airborne aerosol mass spectrometer (AMS) with light-scattering detection
}

\author{
Jin Liao ${ }^{1,2, a, b}$, Charles A. Brock ${ }^{1}$, Daniel M. Murphy ${ }^{1}$, Donna T. Sueper ${ }^{3}$, André Welti ${ }^{1,2, c}$, and Ann M. Middlebrook ${ }^{1}$ \\ ${ }^{1}$ NOAA Earth System Research Laboratory (ESRL), Chemical Sciences Division, Boulder, CO 80305, USA \\ ${ }^{2}$ Cooperative Institute for Research in Environmental Sciences, University of Colorado at Boulder, Boulder, CO 80309, USA \\ ${ }^{3}$ Aerodyne Research Inc., Billerica, MA 01821, USA \\ a now at: Universities Space Research Association, Columbia, MD 21046, USA \\ ${ }^{b}$ now at: NASA Goddard Space Flight Center, Atmospheric Chemistry and Dynamic Laboratory, Greenbelt, MD 20771, USA \\ ${ }^{c}$ now at: Leibniz Institute for Tropospheric Research, Department of Physics, Leipzig, 04318, Germany
}

Correspondence to: Ann M. Middlebrook (ann.m.middlebrook@noaa.gov)

Received: 14 December 2016 - Discussion started: 1 March 2017

Revised: 30 August 2017 - Accepted: 31 August 2017 - Published: 17 October 2017

\begin{abstract}
A light-scattering module was coupled to an airborne, compact time-of-flight aerosol mass spectrometer (LS-AMS) to investigate collection efficiency (CE) while obtaining nonrefractory aerosol chemical composition measurements during the Southeast Nexus (SENEX) campaign. In this instrument, particles scatter light from an internal laser beam and trigger saving individual particle mass spectra. Nearly all of the single-particle data with mass spectra that were triggered by scattered light signals were from particles larger than $\sim 280 \mathrm{~nm}$ in vacuum aerodynamic diameter. Over 33000 particles are characterized as either prompt $(27 \%)$, delayed (15\%), or null (58\%), according to the time and intensity of their total mass spectral signals. The particle mass from single-particle spectra is proportional to that derived from the light-scattering diameter $\left(d_{\mathrm{va}-\mathrm{LS}}\right)$ but not to that from the particle time-of-flight $(\mathrm{PToF})$ diameter $\left(d_{\mathrm{va}-\mathrm{MS}}\right)$ from the time of the maximum mass spectral signal. The total mass spectral signal from delayed particles was about $80 \%$ of that from prompt ones for the same $d_{\mathrm{va}-\mathrm{LS}}$. Both field and laboratory data indicate that the relative intensities of various ions in the prompt spectra show more fragmentation compared to the delayed spectra. The particles with a delayed mass spectral signal likely bounced off the vaporizer and vaporized later on another surface within the confines of the ionization source. Because delayed particles are detected by the mass spectrometer later than expected from their $d_{\mathrm{va}-\mathrm{LS}}$ size, they can affect the interpretation of particle
\end{abstract}

size $(\mathrm{PToF})$ mass distributions, especially at larger sizes. The $\mathrm{CE}$, measured by the average number or mass fractions of particles optically detected that had measurable mass spectra, varied significantly $(0.2-0.9)$ in different air masses. The measured CE agreed well with a previous parameterization when $\mathrm{CE}>0.5$ for acidic particles but was sometimes lower than the minimum parameterized $\mathrm{CE}$ of 0.5 .

\section{Introduction}

Aerosol size, chemical composition, and mass loading are important parameters used to estimate the impact of aerosols on direct (aerosol-radiation) and indirect (aerosol-cloud) climate effects (e.g., Ramanathan et al., 2001). The spatial and temporal distribution of ambient aerosols is highly inhomogeneous due to different sources, meteorological conditions, atmospheric processes, and their relatively short atmospheric lifetimes. The Aerodyne aerosol mass spectrometer (AMS) is a fast time response instrument capable of quantifying sizeresolved nonrefractory aerosol chemical composition (e.g., Jayne et al., 2000; Jimenez et al., 2003; Drewnick et al., 2005; Canagaratna et al., 2007) and has been widely used to measure the real time aerosol ensemble organic, sulfate, nitrate, ammonium, and chloride (non-sea-salt) mass loadings globally (e.g., Zhang et al., 2007a; Jimenez et al., 2009). 
Evaluation of aerosol mass loading accuracy measured by the AMS is important to estimate the impact of aerosols on climate, biogeochemical health, and aerosol formation processes such as aerosol hygroscopicity (Levin et al., 2014; Brock et al., 2016) and aerosol acidity (Hennigan et al., 2015; Zhang et al., 2007b).

The basic principle of the AMS method is to focus ambient aerosols with an aerodynamic lens onto a hot vaporizer and analyze the evolved gases with an electron-impact ionization mass spectrometer. Not all particles introduced to the inlet are thermally desorbed and the resulting gas-phase molecules ionized. The net overall transmission and detection efficiency is called collection efficiency (CE) and expressed as the product of aerodynamic lens transmission efficiency for spherical particles, the loss of transmission due to particle beam broadening, and the efficiency of detecting a particle that vaporizes on impaction (Huffman et al., 2005). The particle transmission losses in the AMS lens can be determined by the lens particle transmission curve (e.g., Bahreini et al., 2008). Beam width probe experiments (Huffman et al., 2005) found that CE less than $100 \%$ is not due to particle beam broadening but is likely due to particles bouncing off the vaporizer. Therefore, with well-characterized lens transmission efficiency, the dominant uncertainty in $\mathrm{CE}$ is likely to be the particles bouncing on the vaporizer. A varying $\mathrm{CE}$ of particles by the AMS potentially introduces large uncertainty in AMS measurements. CE is quantified by the ratio of the mass (or number) of particles detected by the AMS to that of particles introduced into the inlet (Matthew et al., 2008). It ranged from 0.3 to 1 with the highest frequency around 0.45 in our ambient measurements (Middlebrook et al., 2012). This indicates that the varying $\mathrm{CE}$ in some cases may induce an uncertainty as large as a factor of 3 in the aerosol mass measured by AMS. CE less than $100 \%$ in AMS measurements was previously demonstrated by comparing aerosol mass loadings measured by the AMS with that measured by other instruments such as the particle-into-liquid sampler combined with an ion chromatography analyzer (PiLS-IC) or an optical particle counter (ultra-high-sensitivity aerosol spectrometer or UHSAS) (e.g., Takegawa et al., 2005; Middlebrook et al., 2012). Laboratory and field studies showed that CE values depend on aerosol chemical composition and relative humidity (Matthew et al., 2008; Middlebrook et al., 2012). Based on this, a parameterization for the composition-dependent CE was developed (Middlebrook et al., 2012) and is now commonly applied to ambient AMS measurements. CE obtained by comparison of AMS measurements with other instruments like the PiLS-IC and UHSAS may be affected by the measurement uncertainties of other instruments and lens transmission efficiency. In situ measurements of CE can directly quantify the detection efficiency of particles that impact the vaporizer. In situ CE measurements and evaluation of the CE parameterization are therefore important to reduce the uncertainty in the AMS measurements.
A light-scattering (LS) module has been developed to integrate into AMS instruments (LS-AMS) to detect single particles before they impact on the vaporizer (Cross et al., 2007). The LS-AMS determines the in situ CE by comparing the number (or mass) of particles detected by the mass spectrometer signals to the total number (or mass) of particles detected by the scattered light signals. Using the LS-AMS instrument, the mean values of $\mathrm{CE}$ for ambient particles at three ground sites near Mexico City (Cross et al., 2009), Bakersfield, CA (Liu et al., 2013), downtown Toronto (Lee et al., 2015), and in an eastern Canadian forest (Slowik et al., 2010) were reported to be $0.49,0.52,0.37$, and 0.6, respectively. CE for the Mexico City ground site varied only about $\pm 10 \%$ over the full sampling period (Cross et al., 2009), which may be due to relatively constant ambient aerosol chemical composition. Airborne studies of air masses with widely different chemical composition provide an opportunity for investigating the capability of LS-AMS to measure CE variations.

Beside the ability to determine in situ CE, the LS-AMS has also been used to derive particle density by comparing the optical size with the vacuum aerodynamic size (Cross et al., 2007), distinguish single-particle chemical composition types (Cross et al., 2007; Liu et al., 2013; Freutel et al., 2013), examine internal and external particle mixing properties (Robinson et al., 2013), and validate the interpretation of AMS factors from a positive matrix factorization using cluster analysis of the LS module data (Lee et al., 2015). As this work aims to use LS-AMS to investigate AMS measurement uncertainties, analysis regarding the above perspectives is not included.

This study provides the first airborne single-particle measurements from an LS-AMS instrument. These measurements were performed on board the NOAA WP-3D aircraft sampling various air masses over the continental United States during the Southeast Nexus of Air Quality and Climate (SENEX) campaign in May and June 2013 (Warneke et al., 2016). This study focuses on using single-particle data to investigate airborne AMS measurement uncertainties. CE was measured by LS-AMS during this field study and compared to the CE parameterization based on the aerosol chemical composition and relative humidity (Middlebrook et al., 2012). The single-particle data are also used to examine particles that bounce on the vaporizer and the impact of inefficiently collected particles on the chemical ion signals and the AMS particle time-of-flight data.

\section{Experimental}

For the SENEX field project, a compact time-of-flight AMS (Aerodyne Inc., Billerica, Massachusetts) was integrated aboard the NOAA WP-3D aircraft with a pressure-controlled inlet (Bahreini et al., 2008) and an LS module. With the LS module, the AMS is capable of not only measuring the ensemble chemical composition and speciated mass distribu- 
tions but also detecting the chemical composition and size of single particles with light-scattering intensities above a predetermined threshold. Detailed descriptions of the AMS instrument are provided in previous publications (Jayne et al., 2000; Jimenez et al., 2003; Drewnick et al., 2005; Bahreini et al., 2009) and only the differences are pointed out here. Compared to most AMS instruments, our instrument has a longer chamber, with a distance from the chopper wheel to the laser beam of $26.5 \mathrm{~cm}$ and from the chopper wheel to the particle vaporizer of $39.5 \mathrm{~cm}$, the locations of which are shown in Fig. S1 in the Supplement. The added lightscattering module is very similar to that described in Cross et al. (2007) and Cross et al. (2009), with the single-particle data acquisition triggered by the intensity of the scattered light signal as described by Liu et al. (2013). The major differences in the configuration were a smaller and more rigid optical table mounted directly onto the AMS chamber with a cover and locking screws to mount the ellipsoidal and external mirrors and laser to ensure the stability of these components during airborne measurements. In order to fit the AMS with the LS module into the aircraft, we built a shorter extension for the laser beam dump, which was redesigned as a small, baffled, multi-angled chamber containing several knife edges, all painted matte black.

The data acquisition software version used during SENEX was 4.0.30, which included hourly measurement of both the single ion area and the detector baseline along with the mass scale calibration. The threshold setting for saving MS signals with the AP240 data acquisition card (Acqiris, Geneva, Switzerland) was two bits above baseline for all the data. In addition to being checked hourly during each flight, the integrated detector signal for single ion pulses (single ion area in units of bitns ion ${ }^{-1}$ ) was measured during preflight and post-flight. Raw mass spectral signals are digitally recorded by the data acquisition card in units of bit ns extraction ${ }^{-1}$ and in post-processing are converted into ions $\mathrm{s}^{-1}$ with the mass spectrometer pulser period per extraction, the number of extractions (adjacent mass spectrometer pulses) that were combined into each spectrum, and the single ion area calibration.

Although the mass spectrometer was tuned prior to the field project, the microchannel plate (MCP) detector set was nearing the end of its life and was replaced in the middle of the project on 17 June. As a precaution, the new MCP set was initially operated with a reduced gain voltage that was increased several times during the rest of the project. Because of this, the detector sensitivity changed during SENEX with the highest sensitivity (where the single ion area $\geq 13$ bit ns ion $^{-1}$ ) for flights between 26 June and 8 July. However, this sensitivity is still relatively low compared to our other field projects; for example, the single ion area for a recent ground-based study (Öztürk et al., 2013) was typically higher than 20 bit ns ion $^{-1}$. Furthermore, the single ion peak shape is not ideal for our C-ToF due to ringing on the higher ion time-of-flight side. Consequently, low detector sensitivity has a nonlinear effect on low ion signals, which was previously reported by Hings et al. (2007). This can lead to ions with low signal to be biased low and ions with high signal to be biased high. The overall AMS response is generally not affected by decreased sensitivity since the calibration ionization efficiency (IE) is linearly proportional to the signal from air over a wide range of sensitivities (see the third-tolast paragraph in this section for details).

Two operating modes of this AMS instrument are the same as for instruments without an LS module. The mass spectrum (MS) mode is used to measure ensemble submicron aerosol mass concentrations, and particle time-of-flight (PToF) mode is used to measure size-dependent submicron mass concentrations. The added light-scattering single-particle (LSSP) mode with the LS-AMS is used to measure single-particle size and nonrefractory mass. During each flight, the AMS was run alternatively among the MS mode, PToF mode, and LSSP mode with one cycle every $5 \mathrm{~min}$. During the first $270 \mathrm{~s}$ of the cycle, the instrument switched between MS (background for $2 \mathrm{~s}$ with the particle beam blocked and sampling for $4 \mathrm{~s}$ ) and PToF (3.5 s with a chopped particle beam) modes, saving ensemble data roughly every $10 \mathrm{~s}$. Then the instrument was run with the LSSP mode for $30 \mathrm{~s}$. The chopper wheel has a $2 \%$ duty cycle slit and rotated with a frequency of $\sim 110 \mathrm{~Hz}$ during both LSSP and PToF modes. The mass spectrometer was pulsed at a frequency of $62.5 \mathrm{kHz}$ and mass spectra were added together for two ToF pulser periods prior to saving, resulting in $32 \mu$ s between mass spectra for each saved LSSP or PToF chopper cycle. The PToF data were combined for all chopper cycles during the saving period resulting in speciated mass distributions over the full submicron size range, whereas LSSP data were saved for each chopper cycle when the intensity of the scattered light signal was above the data acquisition threshold. Table 1 summarizes the relevant LSSP parameters and definitions used here and in other recent studies.

In LSSP mode, the particle beam is chopped and particles traverse an unfocussed beam of a continuous, solidstate, $405 \mathrm{~nm}$ wavelength, $50 \mathrm{~mW}$ laser (CrystaLaser model DL405-050-0 with a CL-2005 power supply, Reno, NV) placed perpendicular to the particle beam prior to particles entering the vaporization/ionization section of the AMS vacuum chamber. The scattered light from the particles is focused with an ellipsoidal mirror onto a photomultiplier tube (PMT). As first employed by Liu et al. (2013), the scattered light intensity is monitored and, when above a specified threshold, triggers saving all of the chemical ion signals (mass spectra) obtained during the course of the current $\sim 9.1 \mathrm{~ms}$ chopper cycle along with the corresponding scattered light signal from the PMT. An example of the raw LSSP data for a prompt particle from SENEX is shown in Fig. S2. For each triggered event, the mass spectra from that chopper cycle are analyzed during post-processing. The spectrum with the maximum MS signal is located and then integrated within the adjacent \pm 5 mass spectra of that maximum to generate the total chemical ion signal for the triggering particle. 
Table 1. Summary of AMS light-scattering results.

\begin{tabular}{|c|c|c|c|c|}
\hline & This work & $\begin{array}{l}\text { Cross et al. } \\
(2009)\end{array}$ & $\begin{array}{l}\text { Liu et al. } \\
(2013)\end{array}$ & $\begin{array}{l}\text { Lee et al. } \\
(2015)\end{array}$ \\
\hline Sampling location & Over SE US & Mexico City & $\begin{array}{l}\text { Bakersfield, } \\
\text { CA }\end{array}$ & Toronto \\
\hline Mass spectrometer & $\mathrm{C}-\mathrm{ToF}$ & $\mathrm{C}-\mathrm{ToF}$ & HR-ToF & $\begin{array}{l}\text { HR-ToF } \\
\text { (SP laser off) }\end{array}$ \\
\hline Chopper-to-vaporizer length $(\mathrm{cm})$ & 39.5 & 29.0 & NR & 39.5 \\
\hline LS particle events analyzed & $33861^{\mathrm{a}}$ & 12853 & 271641 & 84218 \\
\hline$d_{\mathrm{va}}$ for $50 \% \mathrm{LS}$ detection efficiency $(\mathrm{nm})$ & 360 & 370 & 430 & 340 \\
\hline Min. no. of ions for MS detection & $38^{\mathrm{b}}$ & NR & 6 & 6 \\
\hline Definition of "delayed" & $\begin{array}{l}t>\left(t_{\text {est }}+t_{\text {offset }}\right) \\
+3 \times \text { Gauss. width }\end{array}$ & $t>\left(t_{\text {est }}+t_{\text {offset }}\right)$ & $\begin{array}{l}t>1.20 \times \\
\left(t_{\text {est }}+t_{\text {offset }}\right)\end{array}$ & $\begin{array}{l}t>\left(t_{\text {est }}+t_{\text {offset }}\right) \\
+3 \times \text { Gauss. width }\end{array}$ \\
\hline Offset time (ms) & 0.35 & 0.2 & $\mathrm{NR}$ & $\sim 0.42$ \\
\hline Prompt fraction & $27 \%$ & $23 \%$ & $46 \%$ & $33.6 \%$ \\
\hline Delayed fraction & $15 \%$ & $26 \%$ & $6 \%$ & $0.4 \%$ \\
\hline Null fraction & $58 \%$ & $51 \%$ & $48 \%$ & $63.2 \%$ \\
\hline
\end{tabular}

NR is not reported.

a Total particle number analyzed of research flights, 26 June-8 July.

b Average minimum ions for MS detection of research flights, 26 June- 8 July.

Sometimes two or more particles passed through the chopper slit during one chopper cycle and triggered the saving of LSSP data. These cases are found during post-processing as having more than one peak in the scattered light signal and are called coincident particles. Flight average coincident particle fractions ranged from less than $1 \%$ to about $3 \%$ in this study. Unfortunately, the analysis software currently does not correctly account for spectra in coincident cases because only one spectrum of the maximum MS signal is generated per chopper cycle. This spectrum can be from either of the particles since the timing and intensity of the scattered light signals do not necessarily correspond to the magnitude of chemical ion signals. Hence, the coincident particle data are excluded from this analysis.

Using LSSP mode, there are three ways to measure particle size: (1) vacuum aerodynamic diameter based on the particle velocity from the mass spectral information (a.k.a. the traditional AMS vacuum aerodynamic diameter or $d_{\mathrm{va}-\mathrm{MS}}$ ), (2) vacuum aerodynamic diameter based on the particle velocity from the light-scattering information (light-scattering vacuum aerodynamic diameter or $d_{\mathrm{va}-\mathrm{LS}}$ ), and (3) optical diameter (or $d_{\mathrm{o}}$ ) from the scattered light intensity of individual particles. The vacuum aerodynamic diameter is defined for the AMS by Eq. (44) from DeCarlo et al. (2004):

$d_{\mathrm{va}}=d_{\mathrm{m}} \times \frac{\rho_{\mathrm{eff}}}{\rho_{0}}$,

where $d_{\mathrm{m}}$ is the electrical mobility diameter, $\rho_{\text {eff }}$ is the effective particle density (in $\mathrm{g} \mathrm{cm}^{-3}$ ), and $\rho_{0}$ is the standard density $\left(1 \mathrm{~g} \mathrm{~cm}^{-3}\right)$. The vacuum aerodynamic diameter is related to the particle velocity measured by the AMS (Jayne et al., 2000; DeCarlo et al., 2004), and the additional subscripts of MS and LS are used here to indicate the method of calculating particle velocity. For $d_{\mathrm{va}-\mathrm{MS}}$, the particle velocity is determined from the time of the maximum intensity in the mass spectral signal (also known as PToF time or $\left.t_{\mathrm{ms}}\right)$ divided by the distance between the chopper wheel and the vaporizer $\left(L_{\mathrm{vp}}\right)$ and this velocity was calibrated using polystyrene latex spheres (PSLs) of known sizes. In this manner, mass distributions as a function of $d_{\mathrm{va}-\mathrm{MS}}$ or $d_{\mathrm{m}}$ can be determined from AMS instruments in PToF mode without the LS module (Jayne et al., 2000). For $d_{\mathrm{va}-\mathrm{LS}}$, the particle velocity is calculated from the time of the maximum intensity of the scattered light signal $\left(t_{\mathrm{LS}}\right)$ divided by the distance between the chopper wheel and the laser beam $\left(L_{\mathrm{LS}}\right)$. This velocity can be calibrated with PSLs in a similar manner to $d_{\mathrm{va}-\mathrm{MS}}$ (Cross et al., 2007), but unfortunately we did not collect the appropriate LSSP data from PSLs to calibrate $d_{\mathrm{va}-\mathrm{LS}}$ during the SENEX project. Hence, we used an alternate method to determine $d_{\text {va-LS }}$ which involved plotting histograms of $t_{\mathrm{LS}}$ for laboratory particles that rapidly evaporated in the mass spectrometer (discussed in Sect. 3.1.1). The third type of measurement of particle size, the optical diameter or $d_{0}$, can be obtained from a calibration of the scattered light intensity and compared to $d_{\mathrm{va}-\mathrm{MS}}$ to obtain information about the particle density using Eq. (1) (Cross et al., 2007).

The laser is used to count particles in all three sampling modes every time the intensity of the scattered light signal is above the specified threshold, except that the small fraction of coincident particles in LSSP mode are counted as only one particle. Counts per second in LSSP mode are lower than those in the adjacent MS modes due to dead time when particles cannot be counted while individual LSSP events are being saved. This duty cycle factor averaged $35 \%$ and decreased with increasing number concentration. Therefore, the average duty cycle factor based on the preceding 
and following MS cycles was used to calculate the numberbased or mass-based mass distributions from LSSP mode (see Sect. 3.2.2).

The IE of the instrument was calibrated with pure, dry ammonium nitrate particles several times before, during, and after the field project. The Igor ToF AMS calibration analysis software version 3.1.5 was used with the PToF-calibrated size $\left(d_{\mathrm{va}-\mathrm{MS}}\right)$ to calculate the nitrate IE. When all of the calibration data were combined, the IE was linearly proportional over a wide range of detector sensitivities to the air beam (AB) signal at $m / z 28$ (signal from air) with an intercept: IE $=1.29 \times 10^{-7}+1.24 \times 10^{-12} \times \mathrm{AB}$. For a typical $\mathrm{AB}$ value of $4.5 \times 10^{5} \mathrm{~Hz}$, the IE for nitrate was about $7 \times 10^{-7}$ ions molec $^{-1}$. The unit mass resolution MS and PToF data were analyzed using the Igor ToF AMS analysis toolkit (a.k.a. Squirrel) version 1.52L. For the MS and PToF data, the default AMS fragmentation table described by Allan et al. (2004) was adjusted slightly for each flight for the measured fragmentation pattern from water and measured contributions of various species to the filtered air signals. The current default values for the relative ionization efficiency (RIE) of sulfate, organic, and nonrefractory chloride $(1.2,1.4$, and 1.3 , respectively) were used but the values of nitrate and ammonium were changed to 1.05 and 3.9.

The LSSP data were processed using the Igor LS analysis toolkit (a.k.a. Sparrow) version 1.04F, with a modification to account for the longer particle flight chamber. The default list of $m / z$ values in Sparrow was used to generate the mass spectra from individual particles. LSSP mass spectra are then processed using the default fragmentation table matrix and the above RIEs, except the contribution from air is removed from the matrix since only the mass spectral signals from the particle are selected. The backgrounds from the longest and/or shortest times at each $m / z$ in the LSSP spectra from a single chopper cycle are subtracted from the particle region in the same way the background is subtracted for standard PToF data. To calculate single-particle mass from the LSSP size, $d_{\mathrm{va}-\mathrm{LS}}$, the effective particle density is estimated to be $1.55 \mathrm{~g} \mathrm{~cm}^{-3}$ from a calculated weighted average density of the SENEX AMS data set that was composed of 50-70\% organic material (estimated density of $1.25 \mathrm{~g} \mathrm{~cm}^{-3}$ from Cross et al., 2007; Kiendler-Scharr et al., 2009; Zelenyuk et al., 2008 ) and 30-50\% inorganic material (primarily dry ammonium sulfate with a density of $1.75 \mathrm{~g} \mathrm{~cm}^{-3}$ from Perry and Green, 1997).

The LS-AMS was on board the NOAA WP-3 aircraft and flew over the continental US to sample a variety of air masses during SENEX from June to July 2013, as part of the large collaboration study Southeast Atmospheric Study (SAS). Detailed information of the field campaign is provided in Warneke et al. (2016) and http://www.esrl.noaa. gov/csd/projects/senex/. Over the course of the project, there were 17 research flights. Besides the AMS measurements presented here, dry particle number distributions from $\sim 0.07$ to $1.0 \mu \mathrm{m}$ were measured with a UHSAS (Brock et al., 2016) on board the same aircraft and are used to derive the particle mass distributions for comparison in this study. For comparisons between the AMS and UHSAS instruments, we account for the AMS lens transmission efficiency (Liu et al., 2007), which was measured for our lens to be similar to the predicted transmission (Bahreini et al., 2008). Since the AMS sensitivity was poor at the beginning of the field project and UHSAS data were not available for the last flight, the data reported here are from seven flights from 26 June until 8 July (Flights 10-16).

\section{Results and discussion}

\subsection{LSSP signal processing and categorization of particles}

\subsubsection{Timing of the LSSP signals, particle $d_{\mathrm{va}-M S}$ and $d_{\text {va-LS }}$ sizing, and categories based on time}

Two of the ways to determine particle size in the LS-AMS involve measuring the particle velocity using the particle timeof-flight distances between the chopper and the vaporizer $\left(L_{\mathrm{vp}}\right)$ or between the chopper and the laser $\left(L_{\mathrm{LS}}\right)$ and the corresponding time of the maximum MS signal $\left(t_{\mathrm{ms}}\right)$ or the maximum LS signal $\left(t_{\mathrm{LS}}\right)$ (Cross et al., 2007). Particles are accelerated into the vacuum chamber at the lens exit based on their size (smaller particles are accelerated to faster speeds than larger particles) and particle velocities are assumed to be constant by the time they reach the chopper wheel. Their velocities based on the MS signals $\left(=L_{\mathrm{vp}} / t_{\mathrm{ms}}\right)$ were calibrated for $d_{\mathrm{va}-\mathrm{MS}}$ size using PSL particles. To calculate $d_{\mathrm{va}-\mathrm{MS}}$ from individual particles, they must have viable chemical ion signals (mass spectra or MS). However, they do not need to have viable MS signals in order to measure $d_{\mathrm{va}-\mathrm{LS}}$ based on the timing of their LS signals (as shown below).

The time the particle passes through the laser beam $\left(t_{\mathrm{LS}}\right)$ can be used to estimate the arrival time at the vaporizer $\left(t_{\text {est }}\right)$ as follows:

$t_{\mathrm{est}}=t_{\mathrm{LS}} \times \frac{L_{\mathrm{vp}}}{L_{\mathrm{LS}}}$,

where $t_{\mathrm{LS}}, L_{\mathrm{vp}}$, and $L_{\mathrm{LS}}$ are defined as above. For our chamber dimensions, $t_{\mathrm{est}}=1.49 \times t_{\mathrm{LS}}$. Times of the maximum LS and MS signals for an example of LSSP data are indicated in Fig. S2 along with $t_{\text {est }}$, which is earlier than the maximum MS signal time $\left(t_{\mathrm{ms}}\right)$.

Figure 1 displays histograms of the time differences between the time of the maximum MS signal $\left(t_{\mathrm{ms}}\right)$ and the estimated arrival time $\left(t_{\mathrm{est}}\right)$ based on Eq. (2) for polydispersed, laboratory-generated, and SENEX particles. A similar histogram was previously generated, described, and shown in the Supplement by Lee et al. (2015). Ammonium nitrate particles are known to have a CE around $100 \%$ whereas ammonium sulfate particles have a CE around $25 \%$ (Matthew et al., 2008) and their histograms of the time differences are not the 


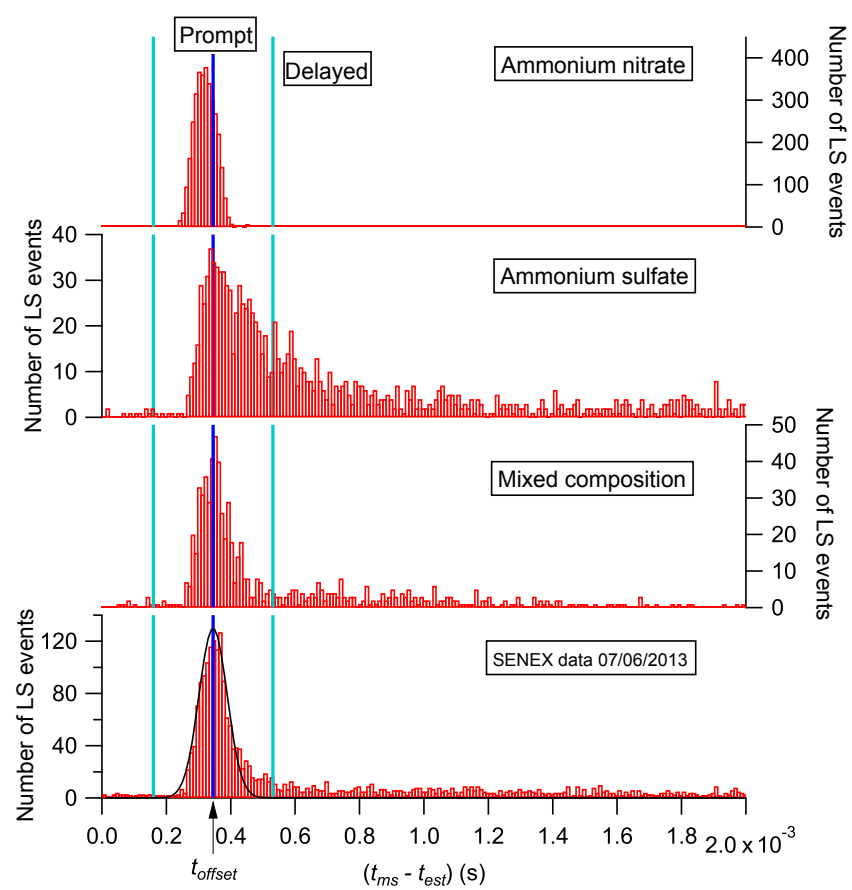

Figure 1. Histograms (red) of the time for the maximum mass spectral signal $\left(t_{\mathrm{ms}}\right)$ minus the estimated time $\left(t_{\mathrm{est}}\right)$ for particles to arrive at the vaporizer based on the time of the maximum intensity of the scattered light signal for particles composed of pure ammonium nitrate, pure ammonium sulfate, mixed composition (organic dicarboxylic and carbonyl acids, ammonium organic acid salts, ammonium sulfate, and ammonium nitrate), and the SENEX flight data on 6 July 2013. The Gaussian fit to the SENEX histogram is shown in black. The offset time ( $\left.t_{\text {offset }}\right)$ from the fit for the SENEX data (the dark blue vertical line) is similar to the offset times for the laboratory particles. The distances between dark blue line and cyan lines are three times the width of the SENEX Gaussian fit. Prompt particles are defined as those with times between the cyan lines and delayed particles are detected at later times on the right-hand side of the distribution.

same. Several features of the histogram distribution for ammonium nitrate particles are apparent: there are no particles at large time differences, the histogram has a Gaussian shape, the width at the base of this fit $(\sim 0.18 \mathrm{~ms})$ is approximately the time available for particles to pass through the chopper slit ( $\sim 0.17 \mathrm{~ms})$, and the mean of the Gaussian fit to the histogram is a nonzero offset time ( $\left.t_{\text {offset }}\right)$. The ammonium sulfate histogram has a maximum near the mean of the ammonium nitrate distribution and has a significant tail of particles that were detected at later times. The two other histograms (mixed composition and SENEX particles) are not as narrow as the ammonium nitrate histogram and have fewer particles than the ammonium sulfate histogram at slower times.

For the SENEX particles, the mean of its Gaussian distribution fit, $t_{\text {offset }}$, is $0.35 \mathrm{~ms}$ (see Table 1) and is depicted as the vertical blue line in all four histograms of Fig. 1. For ammonium nitrate particles with a $100 \% \mathrm{CE}, t_{\text {offset }}$ is $0.31 \mathrm{~ms}$, slightly smaller than the SENEX offset time. The similar offset times for the four histograms indicate that the times of the maximum MS signal are later than the estimated time by a consistent amount. Once the offset time is taken into account, the times of the maximum MS signals are similar to $t_{\text {est }}$ from Eq. (2) for the ammonium nitrate particles. This implies that the two particle velocities are constant when an offset time is included.

The offset time $(0.3-0.35 \mathrm{~ms})$ is too long to indicate an error in the positions of the laser or the vaporizer and is independent of particle size, as shown later in Fig. 2c. By examining the Gaussian fit reported by Lee et al. (2015), we derived an offset time for that study of about $0.42 \mathrm{~ms}$ (see Table 1). The offset time of $0.2 \mathrm{~ms}$ used by Cross et al. (2009) was not defined in the same way and cannot be compared directly to offsets from the Gaussian fits. The offset time in our data set appears to be systematic and may be related to a number of delays for the MS signals that do not occur for the LS signals. There is some uncertainty in $t_{\mathrm{LS}}$ and $t_{\mathrm{ms}}$ due to not knowing exactly when the particles transited the chopper slit (Cross et al., 2007), which is about $0.17 \mathrm{~ms}$ for our system. This is apparent in the width of the Gaussian distribution for the ammonium nitrate particles (top of Fig. 1). For prompt particles, not including the uncertainty in the time for particles to pass through the chopper, the largest uncertainty in PToF sizing from $t_{\mathrm{ms}}$ is believed to be due to vaporization (Huffman et al., 2005; Day et al., 2011). Vaporization event lengths (defined as full width at half maximum of the single-particle MS signals) depend on the species and can range from $25 \mu$ s for ammonium nitrate particles to less than $60 \mu$ s for ammonium sulfate particles (Drewnick et al., 2015). The additional time needed for the neutral molecules to move from the vaporizer to the electron beam and for ions to move from the ion source to the orthogonal extraction region are likely much shorter than the offset time. Altogether, these times are too short to account for the systematic offset time, so it most likely incorporates some additional time needed to process the single-particle mass spectra during data acquisition in LSSP mode, which may be slightly longer for the HR-ToF AMS used by Lee et al. (2015) than for the C-ToF AMS that we used here.

We used the particle velocity calibration for $d_{\mathrm{va}-\mathrm{MS}}$ to determine $d_{\mathrm{va}-\mathrm{LS}}$ after taking the offset time into account in the following way. The particle velocity calibration for PToF sizing of traditional AMS instruments includes this offset time in the measured $t_{\mathrm{MS}}$. In contrast, $t_{\mathrm{LS}}$ does not include additional time for detecting mass spectral signals, so the calibration coefficients will vary slightly from the traditional $d_{\mathrm{va}-\mathrm{MS}}$ calibration. To determine the $d_{\mathrm{va}-\mathrm{LS}}$ particle size based on the $d_{\mathrm{va}-\mathrm{MS}}$ velocity calibration, an adjustment of the offset time accounting for the chamber dimensions needs to be added to the time of the maximum LS signal: 

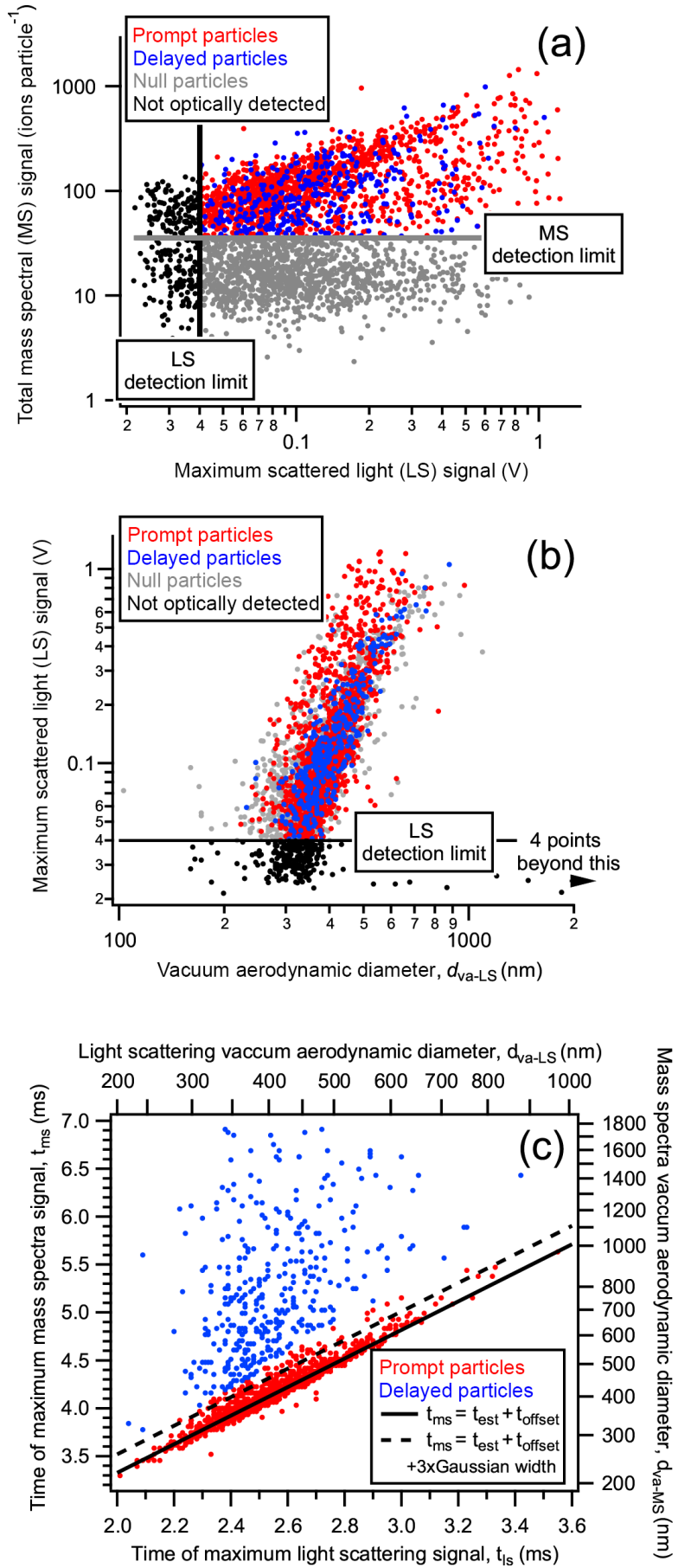

Figure 2. (a) Total LSSP single-particle mass spectral (MS) signal as a function of the maximum intensity of the light-scattering (LS) signal for the data obtained on 6 July 2013. The data are classified by user-specified detection limits and are colored by those below the LS detection limit (black vertical line with black points to the left indicates optically not detected), those below the MS detection limit (gray horizontal line with gray points below indicates null particles), and those defined by the times of the maximum LS and MS signals in Figs. 1 and 2c (red is prompt particles; blue is delayed particles). (b) The maximum scattered light intensity from all LS-triggered events for the flight on 6 July 2013 vs. vacuum aerodynamic diameter from the time of the maximum scattered light intensity, $d_{\mathrm{va}-\mathrm{LS}}$. The limit of optical detection was defined for this paper as having a maximum scattered light intensity above $0.04 \mathrm{~V}$. Particles with maximum scattered light signals below this are defined as "optically not detected" (black points). Other points are colored as in panel (a). (c) Time of the maximum mass spectral signal $\left(t_{\mathrm{ms}}\right)$ vs. the time of the maximum scattered light intensity $\left(t_{\mathrm{ls}}\right)$ and their corresponding vacuum aerodynamic diameter $d_{\mathrm{va}-\mathrm{MS}}$ and $d_{\mathrm{va}-\mathrm{LS}}$ of all chemically detectable particles (prompt and delayed) from the flight on 6 July 2013. Particles below the chemical (null) and optical detection limits are not included in this plot. In the legend, $t_{\mathrm{est}}$ is from Eq. (2) and $t_{\text {offset }}$ is the intercept of the solid line. 
adjusted timing for velocity $\mathrm{LS}_{\mathrm{LS}}+t_{\mathrm{offset}} \times \frac{L_{\mathrm{LS}}}{L_{\mathrm{vp}}}$.

$d_{\mathrm{va}-\mathrm{LS}}$ is then obtained by the $d_{\mathrm{va}-\mathrm{MS}}$ laboratory calibration values and the derived particle velocity accounting for the offset time as

velocity $_{\mathrm{LS}}=\frac{L_{\mathrm{LS}}}{t_{\mathrm{LS}}+t_{\mathrm{offset}} \times \frac{L_{\mathrm{LS}}}{L_{\mathrm{vp}}}}$.

We thus have two measurements of vacuum aerodynamic diameter $\left(d_{\mathrm{va}-\mathrm{MS}}\right.$ and $\left.d_{\mathrm{va}-\mathrm{LS}}\right)$ that can provide further information about the LSSP particles detected by the AMS. While this derivation is not as straightforward as a direct calibration of the particle velocity from light scattering for PSL particles, we verified that the method worked well when calculating $d_{\mathrm{va} \text {-LS }}$ for PSLs using LSSP data from another velocity$d_{\text {va-MS }}$ PSL calibration data set for a subsequent field project. Furthermore, a direct calibration of $d_{\mathrm{va}-\mathrm{LS}}$ would be limited to particle sizes above the light-scattering detection limit and cannot include air, which is used in the $d_{\mathrm{va}-\mathrm{MS}}$ calibration. The true particle velocity in the AMS, however, does not include $t_{\text {offset }}$ and is obtained simply as $L_{\mathrm{LS}} / t_{\mathrm{LS}}$, with about $\pm 0.17 \mathrm{~ms}$ uncertainty for our chopper duty cycle ( $2 \%)$ and rotational speed $(\sim 120 \mathrm{~Hz})$ in the time that the particles pass through the chopper slit (Cross et al., 2007). This timing uncertainty results in a size uncertainty of $9 \%$ for both $d_{\mathrm{va}-\mathrm{MS}}$ and $d_{\mathrm{va}-\mathrm{LS}}$.

In addition to sizing the particles, the timing differences of the maximum MS signals minus the estimate time for particles to arrive are used to define if particles appear "promptly", are "delayed", or are "early." The distinction between these categories of particles is based on if this time difference is within the boundaries of the Gaussian fit (prompt) or outside of the boundary (early or delayed). The boundaries are defined explicitly at $t_{\text {offset }} \pm 3 \times$ the Gaussian width, which is the same definition as used by Lee et al. (2015) (see Table 1). Early particles are outside the lower boundary (here it is $0.16 \mathrm{~ms}$ ) and delayed particles are outside the upper boundary $(0.53 \mathrm{~ms}$ here). These two boundaries are the vertical cyan lines in Fig. 1, and the categories based on these boundaries are described in more detail in later sections. Since very few particles in the SENEX data were early, they are not included in this analysis.

\subsubsection{Intensities of the LSSP signals, particle $d_{0}$ sizing, and categories based on intensity}

The intensities of LSSP signals are important for sizing and categorizing particles from the LSSP data sets. The total (integrated) MS signals from individual particles are shown vs. the maximum intensities of their LS signals in Fig. 2a for the flight on 6 July 2013. The particles are distinguished by the optical (LS) and chemical ion (MS) detection limits. In LSSP mode, the threshold for data saving was set low to save particles with scattered light signals near the detection limit and therefore some of the saved LSSP data were triggered by noise. For post-processing, the optical detection limit for SENEX is defined as a maximum scattered light intensity $>0.04 \mathrm{~V}$ and a signal-to-noise ratio $(S / N) \geq 3$. Less than $10 \%$ of the LSSP data were triggered by noise (black points in Fig. 2) and are excluded from further analysis.

The maximum intensity of the scattered light signal can be used as an indicator of particle size $\left(d_{0}\right)$. The correlation between the maximum intensity of the single-particle scattered light signal and the derived particle diameter $d_{\mathrm{va}-\mathrm{LS}}$ from velocity (see Sect. 3.1.1) for all LS-triggered events (red, above the optical detection limit, and black, below the optical detection limit) for the flight on 6 July 2013 is plotted in Fig. 2b. There were a significant number of light-scattering triggers for particles larger than $\sim 280 \mathrm{~nm} d_{\mathrm{va}-\mathrm{LS}}$ and the locus of the distribution of maximum LS signals crossed the optical detection limit at 300 to $350 \mathrm{~nm}$. These optical detection limits are consistent with Liu et al. (2013), who reported that, with a slightly different criterion $(S / N \geq 5)$, the smallest particle ever detected was $180 \mathrm{~nm}$ and the $50 \%$ detection probability was at $430 \mathrm{~nm} d_{\mathrm{va}}$. Figure $2 \mathrm{~b}$ shows that $d_{\mathrm{va}-\mathrm{LS}}$ has a generally positive correlation with the maximum intensity of the scattered light signal as scattered light signals are approximately proportional to cube of the particle physical diameter. The maximum scattered light intensities varied over a significant range for the same size particles because the system was not optimized for sizing particles optically. Gaussian fits of individual scattered light pulses from the slowest $\left(75-85 \mathrm{~m} \mathrm{~s}^{-1}\right.$ ) particles were about $9-12 \mu$ s wide and the data from the PMT were recorded every $10 \mu$ s, which missed the true maximum of the scattered light pulse for many particles. The scattered light pulse widths and particle velocities indicate that our laser beam was about $0.7-0.9 \mathrm{~mm}$ wide, which is much smaller than for the first LS-AMS study $(\sim 2 \mathrm{~mm}$ wide; Cross et al., 2007). This is still larger than the calculated particle beam width at the laser position (ranging from 0.13 to $0.59 \mathrm{~mm}$; Huffman et al., 2005), indicating that all of the particles should be passing through the laser beam. Therefore, the maximum scattered light intensities were only used as a diagnostic and not used to derive particle size in this study.

Particles above the LS detection limit are further categorized by the intensity of their total MS signals as either being "null" or "chemically detected". Null particles are defined as those above the LS detection limit that do not have total MS signals above the MS detection limit (gray points in Fig. 2a). The categorization of the chemically detected particles into prompt (red points in Fig. 2a and c) or delayed particles (blue points in Fig. 2a and c) is related to the timing of their MS signals (see Sect. 3.1.1). The MS detection limit for single particles varied slightly from flight to flight depending on detector sensitivity; for the flight data shown in Fig. 1 it was 600 bit ns particle $^{-1}$ with a single ion area of 16.9 bit ns ion $^{-1}$ or about 36 ions in the individual parti- 
cle mass spectra. The average LSSP MS detection limit for all flights analyzed is 38 ions (see Table 1). For dry particles composed of pure ammonium nitrate, this MS detection limit corresponds to an individual particle with a minimum size $d_{\mathrm{p}}$ of about $200 \mathrm{~nm}$ or $d_{\mathrm{va}-\mathrm{MS}}$ of about $275 \mathrm{~nm}$.

Particles with detectible LS and MS signals are subsequently categorized by the time of the maximum MS signal as prompt or delayed particles (see Sect. 3.1.1). The time of single particles as measured by the maximum mass spectral signals is plotted against the time of maximum intensity of scattered light signals for the flight on 6 July 2013 in Fig. 2c. The corresponding $d_{\mathrm{va}-\mathrm{MS}}$ and $d_{\mathrm{va}-\mathrm{LS}}$ values are plotted on the right and top axes. The solid line, defined as $t_{\mathrm{ms}}=t_{\mathrm{est}}+t_{\mathrm{offset}}$, is the expected time for the particles to arrive at the vaporizer based on Eq. (2) plus the offset time, and particles with times that fall on or near this line are defined as "prompt" particles. The slope of the solid line is 1.5 , as expected by the ratio of the distances in the AMS between the chopper wheel, laser beam, and vaporizer according to Eq. (2). The intercept is the same offset time as indicated in Fig. 1. The dashed line, defined as $\left(t_{\mathrm{ms}}=t_{\mathrm{est}}+t_{\mathrm{offset}}+3 \times\right.$ Gaussian width), is used to distinguish the particles with times for the maximum mass spectral signal that are significantly later than expected (delayed particles). This delayed time for the maximum mass spectra signal varied over a wide range, from 0.02 to $3.1 \mathrm{~ms}$ with an average of $1.0 \mathrm{~ms}$. The time delays are also apparent in the Fig. 1 histograms of ammonium sulfate, mixed composition, and SENEX data.

Our data are consistent with the hypothesis that delayed particles represent particles that bounce off the vaporizer and subsequently vaporize on another surface in the source region (Cross et al., 2009). The delays are too long to be explained solely by the time it takes particles to vaporize; for example ammonium sulfate vaporizes in less than $60 \mu \mathrm{s}$ (Drewnick et al., 2015). Moreover, our laboratory data show that ammonium nitrate, with no measurable bounce, does not produce delayed particle events (Fig. 1). The ion source is less than $2 \mathrm{~cm}$ in size, so particles that are delayed 500 to $1000 \mu$ s before hitting another surface would have velocities of a few to $20 \mathrm{~m} \mathrm{~s}^{-1}$. Given the range of particle velocities measured in the PToF region of $70-150 \mathrm{~m} \mathrm{~s}^{-1}$ for particles between 1000 and $100 \mathrm{~nm}$ prior to particle impaction on the vaporizer, this represents a loss of as much as $90 \%$ of the initial kinetic energy upon a bounce or multiple bounces within the vaporizer. The lost kinetic energy for the particles that bounced may have been converted into plastic deformation and fracturing (Miyakawa et al., 2013). Alternatively, the delays in appearance of the mass spectral signals could have been due to multiple bounces prior to vaporization (Robinson et al., 2017; Hu et al., 2017). Particles without detectible chemical ion signals could be those that bounced far away from the ionization source cage region and could not be vaporized and ionized efficiently.

\subsubsection{Fractions of prompt, delayed, and null particles}

For the particles that are detected by light scattering, the overall fraction of particles that are detected by the mass spectrometer are affected by particle bounce, refractory composition, and/or ion detection limit. The particles that are detected optically but not detected chemically with the mass spectrometer for any of these reasons are defined as "null" particles (see Fig. 2a). Prompt and delayed particles are defined above in Sect. 3.1.1 by the timing of their mass spectral signals (see Figs. 1 and 2c). Our previous studies suggest that particle phase is an important factor for determining whether or not particles bounce. Larger particles may also have a tendency to bounce more than smaller particles. Some particles contain refractory components (e.g., soot, sea salt, or dust) that do not vaporize at typical AMS vaporization temperatures. If particles are predominantly composed of these species, they will not produce viable mass spectra. The ion detection limit is relevant for particles that are too small to generate sufficient ions from an individual particle. Furthermore, this detection limit varies with the sensitivity of the specific mass spectrometer and likely between different mass spectrometers. Note that the optical detection limit can vary between instruments too.

As discussed later in Sect. 3.2.1 and 3.3.2, the in situ CE from the LS-AMS is defined as the fraction of particles that are detected by the mass spectrometer (all particles detected by light scattering minus the particles without viable mass spectra) divided by the total number of particles detected by light scattering. This definition of $\mathrm{CE}$ is equivalent to the fraction of prompt plus delayed particles. The mass-based in situ CE detected by light scattering is defined as the mass of particles from their MS signals divided by the mass of particles from their volume determined by their light-scattering size, $d_{\mathrm{va}-\mathrm{LS}}$, and an estimated density. Thus, both the fractions of these particles and CE from LSSP data are affected by phase, size, composition, and mass spectrometer sensitivity.

On average the prompt, delayed, and null fractions for this study are $27,15 \%$, and $58 \%$, respectively. These fractions are compared with other LS-AMS studies and the details of all definitions for delayed and prompt particles are listed in Table 1 . The respective fractions are 23,26 , and $51 \%$ in Cross et al. (2009) and 46, 4, and 48\% in Liu et al. (2013). Delayed particles were defined by Cross et al. (2009) as those with $t_{\mathrm{ms}}>\left(t_{\mathrm{est}}+200 \mu \mathrm{s}\right)$, whereas here they are defined as those with $t_{\mathrm{ms}}>\left(t_{\mathrm{est}}+t_{\mathrm{offset}}+3 \times\right.$ Gaussian width $\approx$ $\left.t_{\text {est }}+530 \mu \mathrm{s}\right)$ (see Table 1). Consequently, a higher delayed particle fraction was reported in the Cross et al. (2009) study. The definition of delayed particles in Liu et al. (2013) is difficult to directly compare to our study without information about their offset time. The prompt + delayed fractions are about $50 \%$ for both Cross et al. (2009) and Liu et al. (2013). In this study, the combined fraction is slightly lower (42\%), which may be due to a lower sensitivity and a higher MS 
(chemical) detection threshold that probably leads to higher null rates.

We can get a better understanding of the measured fractions by examining them in more detail. Figure 3 shows the particle types (prompt, delayed, and null) as a function of $d_{\mathrm{va}-\mathrm{LS}}$ for the research flights from 26 June to 8 July. In general, the prompt and delayed fractions decline at small $\left(d_{\mathrm{va}-\mathrm{LS}}<350 \mathrm{~nm}\right)$ or large $\left(d_{\mathrm{va}-\mathrm{LS}}>550 \mathrm{~nm}\right)$ size particles. The single-particle mass is near the chemical signal detection limit in this study due to low sensitivity, so the smallest particle size $\left(d_{\mathrm{va}-\mathrm{LS}}=250 \mathrm{~nm}\right)$ shown here is larger than $d_{\mathrm{va}-\mathrm{LS}}=$ $200 \mathrm{~nm}$ observed by Cross et al. (2009) and particles with $d_{\mathrm{va}-\mathrm{LS}}<250 \mathrm{~nm}$ in this study are mostly null particles (not shown). This is further supported by lower prompt + delayed fractions at the smallest particle size, depicted in Fig. 3, compared to that observed by Cross et al. (2009) and the prompt + delayed fractions at the smallest particle size were even lower for the flights (not shown here) with a lower sensitivity. While the null fraction was relatively high for the 250 $300 \mathrm{~nm}$ size bin, the number of particles in this bin were quite low, so that the overall fraction of prompt + delayed particles is not significantly affected by single particles near the detection limit of the mass spectrometer for SENEX. The LSSP measurements reported for the Bakersfield study had a larger fraction of null particles at the smallest sizes (Liu et al., 2013) and it is unclear if that may also be related to sensitivity. The reduced prompt + delayed fractions at the largest sizes are similar to what was observed by Cross et al. (2009) and Liu et al. (2013) and are likely due to the larger particles having more kinetic energy when arriving at the vaporizer or containing more refractory material (e.g., dust) as suggested by Cross et al. (2009). The maximum fraction of delayed particles appeared at a larger size $(525 \mathrm{~nm})$ than that of prompt particles $(375 \mathrm{~nm})$, which may be a result of more bouncing at larger sizes.

It is important to note that the single-particle mass spectral detection limit affects whether or not individual particles are detected in LSSP mode. However, this is not necessarily a factor for the bulk CE during normal AMS operation because particles are aggregated in both MS and PToF modes. In other words, while single particles may not be detected individually by the mass spectrometer at the smallest sizes, the mass of small particles can be detected when their signals are added together. This is discussed later with the comparisons of mass distributions in Sect. 3.2.2.

\subsubsection{Mass spectral differences between prompt and delayed particles}

Because this study had a significant fraction of delayed particles (about a third of the particles with chemical signals), potential differences in their chemical composition were explored. The average mass spectra of prompt and delayed particles for all SENEX flights analyzed are plotted in Fig. 4a. Delayed particles have relatively higher organic signals at

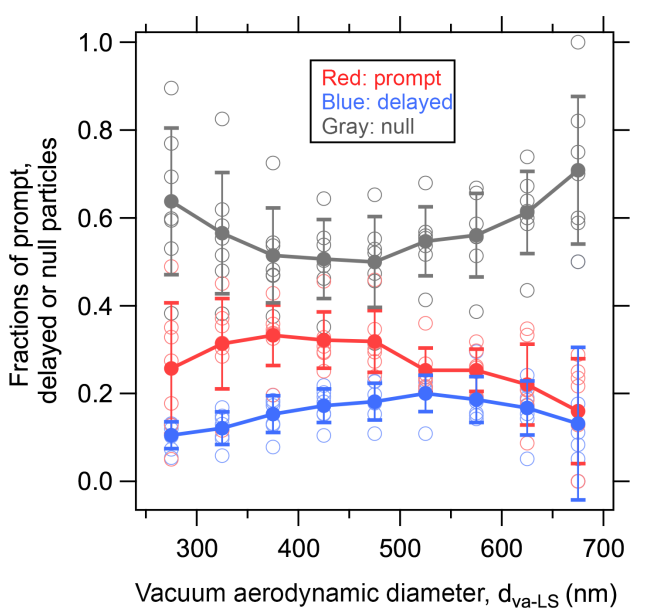

Figure 3. The number fractions of prompt (red), delayed (blue), and null (gray) particles as a function of particle vacuum aerodynamic diameter from the light-scattering module, $d_{\mathrm{va}-\mathrm{LS}}$, for flights from 26 June to 8 July during SENEX. Circles represent the average data of each flight. The solid dots and lines represent the average data of these flights. Error bars represent one SD from the average. The flight on 6 July had the lowest null fractions while the flight on 3 July had the highest null fractions.

$m / z 43,45$, and $>60$, sulfate signals at $m / z 98$ and 81 , and nitrate signals at $m / z$ 46. Prompt particles have relatively higher organic signals at $m / z 44$, sulfate signals at $m / z 48$ and 64 , and nitrate signals at $m / z$ 30. The chemical ion signals of prompt and delayed particles are different on average, which may indicate the mechanism for producing these delayed particles. Two possible explanations are that the delayed particles vaporized at different conditions because they did not vaporize upon initial impaction or that chemical and/or physical differences may have caused these particles to have different bouncing characteristics, resulting in different spectra.

To better interpret the difference in spectra of prompt vs. delayed particles from SENEX, we conducted limited laboratory experiments using nominally identical particles that produced both prompt and delayed spectra. For these experiments, dry, polydispersed particles were generated from a simple aqueous mixture of organic dicarboxylic and carbonyl acids, ammonium organic acid salts, ammonium sulfate, and ammonium nitrate. A total of 1058 light-scattering events were recorded and analyzed using the same criteria as for the SENEX particles except for a lower limit on the number of ions detected in the mass spectra. Of these, about $12 \%$ were below the noise level for actual particle light-scattering events. Of the particles above the light-scattering noise, $47 \%$ were prompt, $13 \%$ were delayed, and $37 \%$ were null. The histogram of the time for the maximum MS signal minus the estimated arrival time for these mixed composition particles is included in Fig. 1 and is more similar in shape to the SENEX data than either pure, dry ammonium nitrate (nar- 


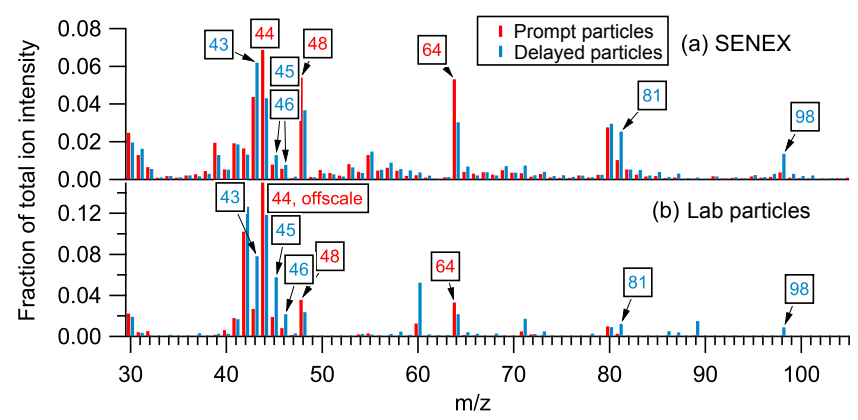

Figure 4. (a) Average mass spectrum (in total ion intensity fraction) of prompt (red) and delayed (blue) particles for the SENEX flights analyzed. The average prompt and delayed spectrum are shifted -0.2 and +0.2 units, respectively, in $\mathrm{m} / \mathrm{z}$ for display clarity. (b) Average mass spectrum (in total ion intensity fraction) of prompt (red) and delayed (blue) laboratory particles composed of internally mixed organic dicarboxylic and carbonyl acids, ammonium organic acid salts, ammonium sulfate, and ammonium nitrate.

row, Gaussian distribution) or ammonium sulfate (distribution with a significant trailing edge tail of delayed particles).

The laboratory data here confirm that nominally identical particles can produce differences in the prompt vs. delayed spectra. The mass spectra for the mixed composition particles are shown in Fig. $4 \mathrm{~b}$ and had similar patterns to the SENEX data, with more prominent peaks at $m / z$ 44, 48, and 64 in the prompt particle spectra and more prominent peaks at $m / z 43,45,46,81$, and 98 and organic peaks with $m / z \geq 60$ in the delayed particle spectra. For these mixed composition particles, the $m / z 30$ peak was slightly more prominent in the prompt particles and $\mathrm{m} / \mathrm{z} 46$ was more prominent in the delayed ones. For the ammonium sulfate particles shown in Fig. 1, the sulfate pattern of high $m / z 81$, and 98 in the delayed particles and high $m / z 48$ and 64 in the prompt particles was consistently observed (not shown). The peaks associated with ammonium (and water) did not appear to show any systematic differences between prompt and delayed particles. For pure ammonium nitrate particles, none of the LSSP data were classified as delayed (see Fig. 1).

Differences in the spectra of prompt and delayed particles were also recently reported for ammonium sulfate and laboratory-generated secondary organic aerosols (SOAs), both with a substantial fraction of delayed particles (Robinson et al., 2017). Indeed, the pattern of sulfate ions between prompt and delayed particles in their study is similar to what is shown in Fig. 4 for the SENEX and mixed composition particles and what we observed with our ammonium sulfate particles (not shown), with the peaks at $m / z 81$ and 98 more prominent in the delayed particles and the peaks at $m / z 48$ and 64 more prominent in the prompt particles. Hence, it appears that the delayed particles have less fragmentation of sulfate and nitrate ions than the prompt ones. Thus, differences between the prompt and delayed spectra in the SENEX data set could be solely due to identical particles vaporizing under distinct conditions. All of the differences in the mass spectra are consistent with more thermal decomposition and fragmentation with prompt particles.

The consistent differences in the mass spectra between prompt and delayed particles from both ambient and nominally identical chemical composition laboratory particles suggests that there are different processes at the vaporizer for prompt and delayed particles. The two likely explanations are that the evolved gas from the delayed particles experienced fewer wall collisions before ionization and/or that the delayed particles vaporized from surfaces at different temperatures. The bottom of the conical vaporizer, where prompt particles should vaporize, is a location where the evolved gas molecules likely experience some wall collisions and could decompose before ionization. Gas molecules from particles vaporizing from other surfaces, such as the top of the vaporizer or the ionization chamber, would experience fewer wall collisions where they could decompose. For both ammonium nitrate and ammonium sulfate particles, there is far more fragmentation when the vapors are contained in a capture vaporizer prior to ionization compared to the conical vaporizer at the same temperature (Hu et al., 2017).

Vaporizer temperatures also affect fragmentation. Lower vaporizer temperatures increase the ions at $\mathrm{m} / z 46$ relative to $\mathrm{m} / \mathrm{z} 30$ for ammonium nitrate and at $\mathrm{m} / \mathrm{z} 80$ and 81 relative to the other ions for ammonium sulfate ( $\mathrm{Hu}$ et al., 2017). Spectra from most but not all organic compounds have more fragmentation when vaporized at $600^{\circ} \mathrm{C}$ than at $200^{\circ} \mathrm{C}$ (Canagaratna et al., 2015). One piece of evidence about vaporization temperature is the width of the vaporization event, which is wider at lower temperatures and is fairly constant above species-dependent temperatures (Drewnick et al., 2015). For the mixed particles that were generated specifically to compare here with the SENEX data, the peaks in the mass spectra as a function of vaporization time were analyzed to check for slower vaporization. A proxy for peak width in the mass spectra (peak area divided by height) was not statistically significant between the prompt and delayed particles, indicating that the vaporization times were roughly comparable. Since a doubling of the peak widths was not observed for the delayed particles here, it is unlikely that they vaporized at temperatures lower than $300^{\circ} \mathrm{C}$ (Drewnick et al., 2015). Because the spectra were saved every $32 \mu$ s and vaporization event lengths in the AMS are on the order of 30-60 $\mu$ s and constant for pure ammonium sulfate particles at temperatures between 400 and $800{ }^{\circ} \mathrm{C}$, the data collected in this brief lab study could not be used to validate the possibility of a less drastic change in vaporization temperature. Equivalent vaporization timescales between prompt and delayed particles along with the same issue of insufficient precision were also reported for the laboratory study of SOA particles (Robinson et al., 2017). The increased fragmentation with a hotter vaporizer could be due to changes in the vaporization process itself or to evolved gas molecules hitting a hotter surface, or both. 
While the timing indicates that the delayed particles may have lost a large amount of kinetic energy or bounced multiple times before vaporization, it is unclear where the delayed particles are vaporizing in the vaporization/ionization source region. The microporous vaporizer itself could provide the first surface for particles to strike after an initial bounce. Another possible surface is the baffle which reduces stray light from the hot filament from reaching the LS detector. This baffle has a small hole to transmit particles into the vaporization/ionization source region and roughly forms the side opposite of the vaporizer. Bounced particles could strike the room-temperature baffle if they exit the vaporizer on a trajectory nearly opposite of the initial particle beam. The interior of the ionization chamber is another possible surface. It has ceramic washers and its mounting points are thermally grounded relative to the baffle, filament, and vaporizer. Heat is conducted radiantly between the various hot surfaces (filament and vaporizer) and the ionization chamber and by conduction through the thin metal of the ionization chamber. The temperature may be different on the sides near and away from the filament. Since we do not have thermocouples on the ionization chamber or the baffle, there are no direct measurements of their temperatures. This makes it difficult to evaluate the relative importance of vaporization temperature compared to fewer wall collisions of the evolved gases from the delayed particles.

\subsubsection{Derived mass from prompt and delayed particles}

The previous section demonstrated that the spectra of prompt and delayed particles identified by the LS-AMS for the SENEX study were different. Here, we examine the measured mass from individual particles distinguished by these two categories. In general, the chemical ion signals from prompt particles were slightly larger than those from delayed particles for a given size determined by $d_{\mathrm{va}-\mathrm{LS}}$. An example comparing the single-particle mass obtained from the mass spectrometer chemical ion signals to that derived from

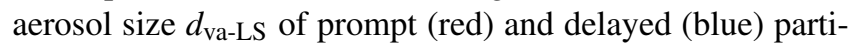
cles for the flight on 6 July 2013 is shown in Fig. 5. Singleparticle masses derived from the mass spectrometer chemical ion signals were well correlated with that derived from measured $d_{\text {va-LS }}$ for prompt particles with a correlation coefficient of 0.87 and a slope of 1.04 with an intercept fixed at zero for this flight. This good correlation between the mass of the particle from the mass spectrum and the size of the particle measured by the time of the maximum scattered light signal indicates that LSSP mode is reasonably quantitative on average on a single-particle basis. The slope depends on the accuracy of the effective particle density, $d_{\mathrm{va}-\mathrm{LS}}$ measurements, and RIEs. For the same size $d_{\mathrm{va}-\mathrm{LS}}$, the mean ratio of individual particle mass from chemical ion signals from the delayed particles (blue points) was 0.78 of the mass from prompt particles (red points). This ratio does not depend on the accuracy of the effective particle density, $d_{\mathrm{va}-\mathrm{LS}}$, or RIE

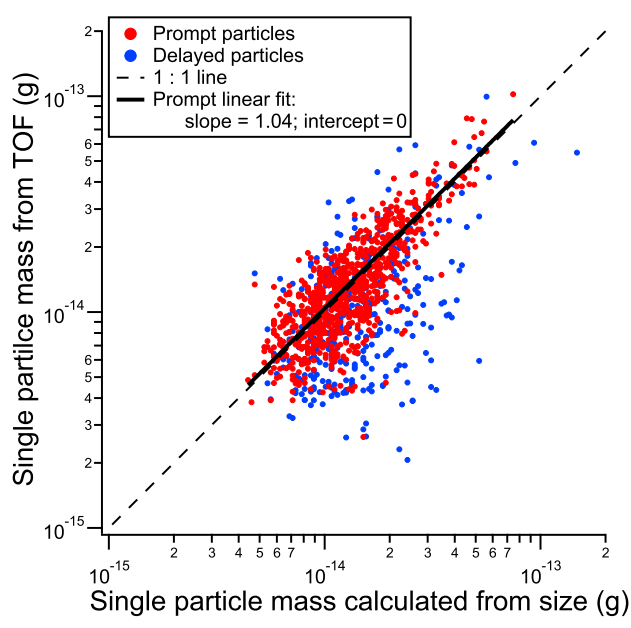

Figure 5. Scatter plot of the single-particle mass from the LSSP mode chemical ion signals vs. that derived from particle size $d_{\mathrm{va}-\mathrm{LS}}$ by assuming a density of $1.55 \mathrm{~g} \mathrm{~cm}^{-3}$ for prompt (red) and delayed (blue) particles during the research flight on 6 July 2013. For prompt particles, the slope of the linear correlation is 1.04 with an intercept set to be 0 .

and was similar in all flights sampling different air masses during this field campaign. While the timing and spectra suggest that these delayed particles vaporized with different conditions, most of the mass was detected.

The delayed particle mass could be lower on average than the prompt particle mass because the evolved gas from the delayed particles was produced in a region where the vapors are not as efficiently ionized by the electron beam. This explanation was recently proposed based on a laboratory study of monodisperse, alpha-pinene SOAs that had a low numberbased CE (0.30), a significant fraction of delayed particles (53\% of all LS particles with MS signals), and a clear trend of more ions per particle for prompt particles than for delayed particles (Robinson et al., 2017). Since the SENEX data are from a range of particle sizes, we normalized the total LSSP ion signals to the cube of their $d_{\mathrm{va}-\mathrm{LS}}$ and plotted the averages as a function of delay time up to $3.5 \mathrm{~ms}$. Figure 6 shows the results from two flights on 6 July and 3 July along with results from ammonium sulfate particles and confirms that delayed particles have a slightly lower total ion signal per unit volume than prompt particles. When considering only delayed particles, all three cases show a negative slope for the total ion signal per unit volume as a function of delay time, but individually the slopes are not significant or marginally statistically significant at the $2 \sigma$ level. The largest change appears to be an average of $\sim 50 \%$ lower signal for particles with the longest delay times for the flight on 3 July. Thus, the efficiency of producing ions from the delayed particles is not always consistently lower than from prompt particles and more experiments are needed to investigate this possible explanation for a reduced mass. It is not clear from the field data why there was a minimal reduction in ion signal; 


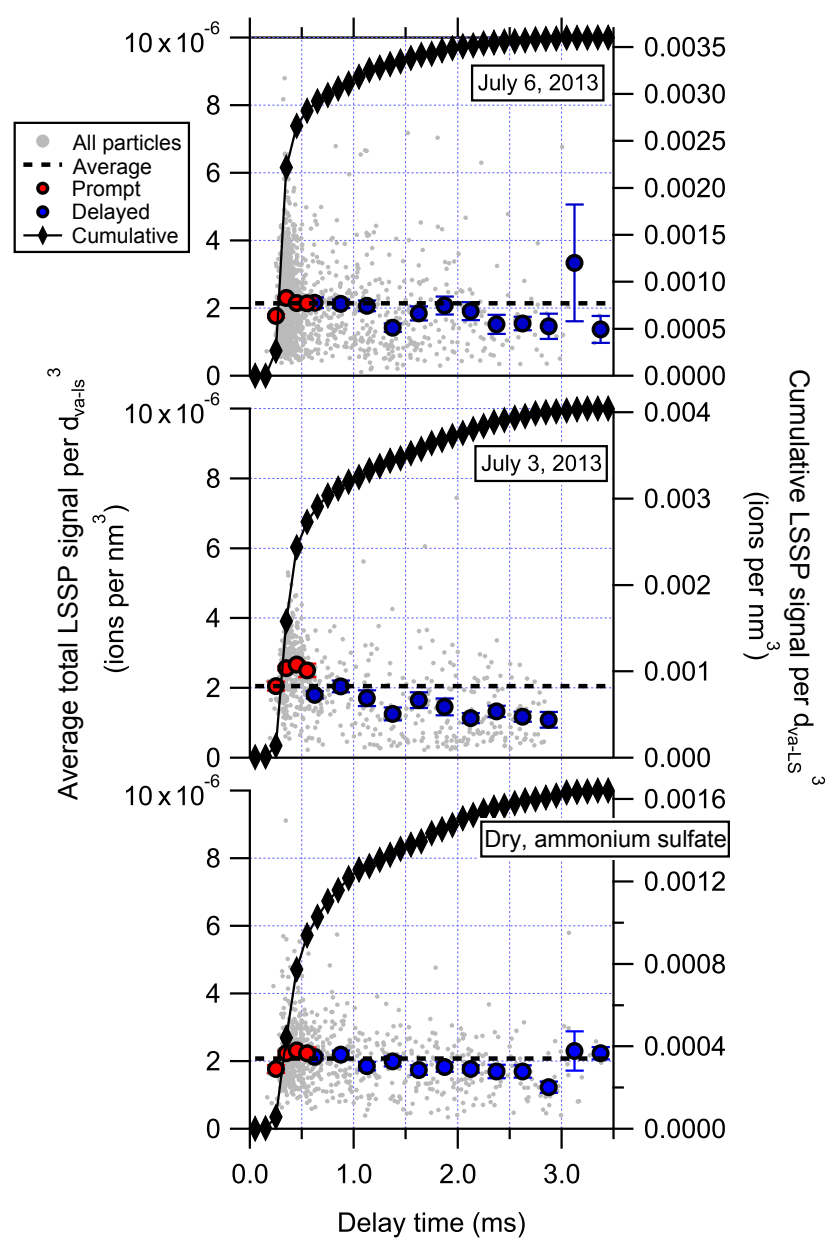

Figure 6. Average total LSSP signals normalized to $\left(d_{\mathrm{va}-\mathrm{LS}}\right)^{3}$ as a function of delay time for the flight with the highest average ambient CE (6 July 2013, top), the flight with the lowest average ambient CE (3 July 2013, middle), and dry ammonium sulfate particles (obtained 13 March 2015, bottom).

inefficient ionization of the vapors that evolved from delayed particles cannot be precluded.

The roughly $20 \%$ reduction in mass of the delayed particles compared to prompt particles could be partly due to some refractory material in the delayed particles that is not measured by the AMS. The bulk mass fraction of refractory black carbon (rBC) was on average $\sim 1 \%$ of the measured aerosol mass for these flights (Warneke et al., 2016), so $\mathrm{rBC}$ does not account for all of the reduced mass. In contrast to the SENEX study, the individual particle mass for delayed particles during the Mexico City study was less than half of that for the prompt particles (Cross et al., 2009). Although the two studies used different definitions for prompt and delayed particles, changing this definition does not alter the measured average chemical ion signals. Also, both studies used the particle size from light-scattering information to calculate the volume. Here the particle size was the vacuum aerodynamic diameter from the time of the maxi- mum scattered light signal ( $\left.d_{\mathrm{va}-\mathrm{LS}}\right)$, whereas for the Cross et al. (2009) work the volume was determined from $d_{\mathrm{va}-\mathrm{LS}}$ and the optical diameter $\left(d_{o}\right)$ from the maximum intensity of the scattered light signal. However, these slightly different particle size-based volume calculations between this study and Cross et al. (2009) will not affect the relative difference in single-particle mass between the prompt and delayed particles. The vaporizers in these two campaigns are designed to be identical. The reasons for much lower delayed particle mass compared to prompt ones remain unclear, but differences in the ambient aerosols measured may contribute to the different delayed particle mass. The Mexico City study was conducted on the ground near the metropolitan area where $\sim 10 \%$ of $\mathrm{PM}_{2.5}$ mass was black carbon (Retama et al., 2015 ) whereas the black carbon was on average $\sim 1 \%$ of the mass for SENEX (Warneke et al., 2016). As the null fraction in Cross et al. (2009) was not higher than in this study and the number-based CE was 0.49, the much lower mass from the delayed particle chemical ion signals observed by Cross et al. (2009) could be due to particles containing more refractory material during the Mexico City study than during SENEX.

\subsection{Characterizing LSSP measurements by comparisons with MS, PToF, and UHSAS data}

\subsubsection{Comparing mass fractions between MS and LSSP modes}

One method of evaluating data from the LSSP mode is to compare the average mass fractions of the main species from the LSSP spectra to those measured in the ensemble MS mode. Mass fractions of nonrefractory aerosol organic, sulfate, ammonium, nitrate, and chloride measured by MS mode vs. LSSP mode for all the SENEX flights analyzed (26 June to 8 July) are shown in Fig. 7. Data in the MS mode adjacent to the LSSP mode were interpolated and compared to the LSSP mode data. Considering that the SD of sulfate mass fraction of standard $\left(\mathrm{NH}_{4}\right)_{2} \mathrm{SO}_{4}$ aerosols measured by LSSP mode is about $10 \%$ and the MS and LSSP mode were not sampling at the same time during the aircraft measurements, the chemical mass fractions of the various species are well correlated between the two modes. When averaged, the 30 s single-particle data sampled in lower troposphere over the continental US could be representative of the ensemble chemical composition mass fractions. The reasons why the ammonium and nitrate mass fractions were slightly higher in the single-particle data are not clear. Since nitrate mass fractions were low for the ensemble data, the uncertainties are relatively larger. Potential explanations for the higher ammonium in the LSSP data may be related to the difference in detected particle size range between LSSP and MS mode or the low sensitivity, which could artificially increase the signals for ammonium (Hings et al., 2007) and may be especially important for the single-particle data. Overall, the 


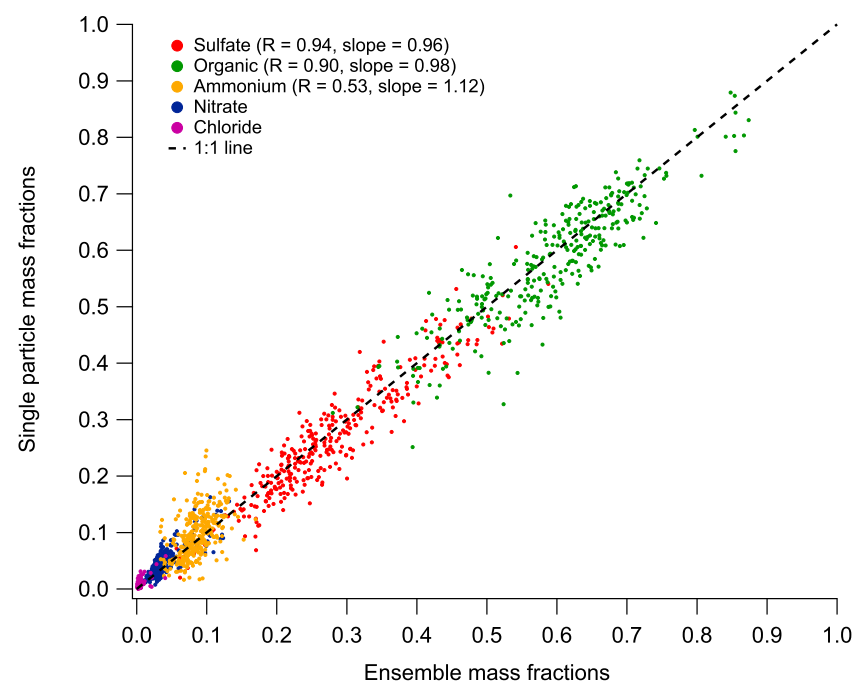

Figure 7. Organic (green), sulfate (red), ammonium (yellow), nitrate (blue), and chloride (purple) mass fractions from singleparticle measurements vs. ensemble measurements from SENEX.

AMS single-particle mass fractions are generally comparable to the ensemble measurements, which was also reported previously for Mexico City (Cross et al., 2009). The good correlation in Fig. 7 indicates that the LSSP data were on average representative of the bulk relative composition in spite of the sampling and processing biases of the single-particle technique.

\subsubsection{Size-resolved mass distribution comparison}

There are three independent ways to generate mass distributions from an AMS instrument with a light-scattering module: (1) traditional PToF mode distributions, with nonrefractory ensemble composition as a function of $d_{\mathrm{va}-\mathrm{MS}}$; (2) particle counts from the LSSP mode laser as a function of $d_{\mathrm{va}-\mathrm{LS}}$, converted into a mass distribution by assuming an effective particle density of $1.55 \mathrm{~g} \mathrm{~cm}^{-3}$; and (3) LSSP mode mass from the single-particle chemical ion signals as a function of $d_{\mathrm{va}-\mathrm{LS}}$. For these comparisons, the PToF distributions were normalized to the mass loadings from MS mode that were derived from the complete fragmentation patterns in the mass spectra (Allan et al., 2004) and the composition-derived CE (Middlebrook et al., 2012). The number-based and massbased LSSP mode mass distributions were scaled to the laser counts from the adjacent MS mode, which did not record $d_{\mathrm{va}-\mathrm{LS}}$ and mass spectrum information, to account for the significant time spent in saving the single-particle information in LSSP mode. This potentially counted particles that were above the light-scattering threshold set in the data acquisition software yet below the optical detection limit set for analyzing the LSSP data. These particles accounted for $4 \%$ of the total LS-triggered events on average and the mass percentage from these particles would be much smaller consid- ering that they are the small particles below optical detection limit. Details on the LSSP mass distribution calculations are in the Supplement. Figure 8a shows these three mass distributions from ambient air below $3000 \mathrm{~m}$ in altitude during the flight on 6 July 2013. A calculated mass distribution from the UHSAS instrument (solid black curve) is also depicted in Fig. 8a, where the UHSAS number distribution is multiplied by the AMS lens transmission efficiency (Liu et al., 2007; Bahreini et al., 2008) and converted to mass as a function of $d_{\mathrm{va}}$ using Eq. (1) and by assuming an effective particle density of $1.55 \mathrm{~g} \mathrm{~cm}^{-3}$.

The four curves in Fig. 8a demonstrate various properties of the LS-AMS system. The LSSP mode number-based mass distribution (red curve) compared to that from the UHSAS instrument (black curve) indicates that the AMS laser system here accounted for the mass from most aerosol particles with $d_{\mathrm{va}-\mathrm{LS}}>440 \mathrm{~nm}$ and essentially none of the mass from particles smaller than $d_{\mathrm{va}-\mathrm{LS}}<280 \mathrm{~nm}$. Our lower limit of size for the detected mass is similar to what was reported by Liu et al. (2013) of 50\% LS detection at $400 \mathrm{~nm}$. Although a few triggers for LSSP data acquisition were recorded for $d_{\mathrm{va}-\mathrm{LS}}$ as small as $\sim 170 \mathrm{~nm}$ (Fig. 2), a very small number of these particles were detected and there generally were no corresponding MS signals until the particles were larger than $d_{\mathrm{va}-\mathrm{LS}} \sim 280 \mathrm{~nm}$. The laser and optics used in the LS-AMS are clearly not optimized to detect small ambient particles. Because the two (black and red) distributions are nearly identical for $d_{\mathrm{va}-\mathrm{LS}}>600 \mathrm{~nm}$, the standard AMS lens transmission function (Liu et al., 2007) appears to be valid for the upper size range. The particle mass from chemical ion signals (gray) is lower than the laser counted particle mass (red) because not all of the particles optically detected produced detectible chemical signals. The ratio of the gray shaded area to the area under the red curve in Fig. 8a is a mass-based measure of the CE and is discussed further in Sect. 3.3.2. The uncertainty introduced by including the particles with scattered light signals below the detection limit for normalizing to the LS counts from the adjacent MS cycles is eliminated when calculating this mass ratio. The AMS PToF mass distribution (dashed curve) has more mass from particles at the large size end $(>700 \mathrm{~nm})$ than all of the other distributions (discussed further below in Sect. 3.3.1).

\subsection{Relevance of LSSP results to standard AMS measurements}

\subsubsection{Measurements of the traditional AMS vacuum aerodynamic diameter $d_{\text {va-MS }}$}

All particles that scatter light are included in the size distributions in Fig. $8 \mathrm{~b}$ and $\mathrm{c}$ to highlight the differences between using the time of the maximum scattered light signal to size the particles $\left(d_{\mathrm{va}-\mathrm{LS}}\right.$ in Fig. $\left.8 \mathrm{~b}\right)$ or the time of the maximum mass spectral signal $\left(d_{\mathrm{va}-\mathrm{MS}}\right.$ in Fig. $\left.8 \mathrm{c}\right)$. The delayed particles create a bias towards the larger size end of the tradi- 

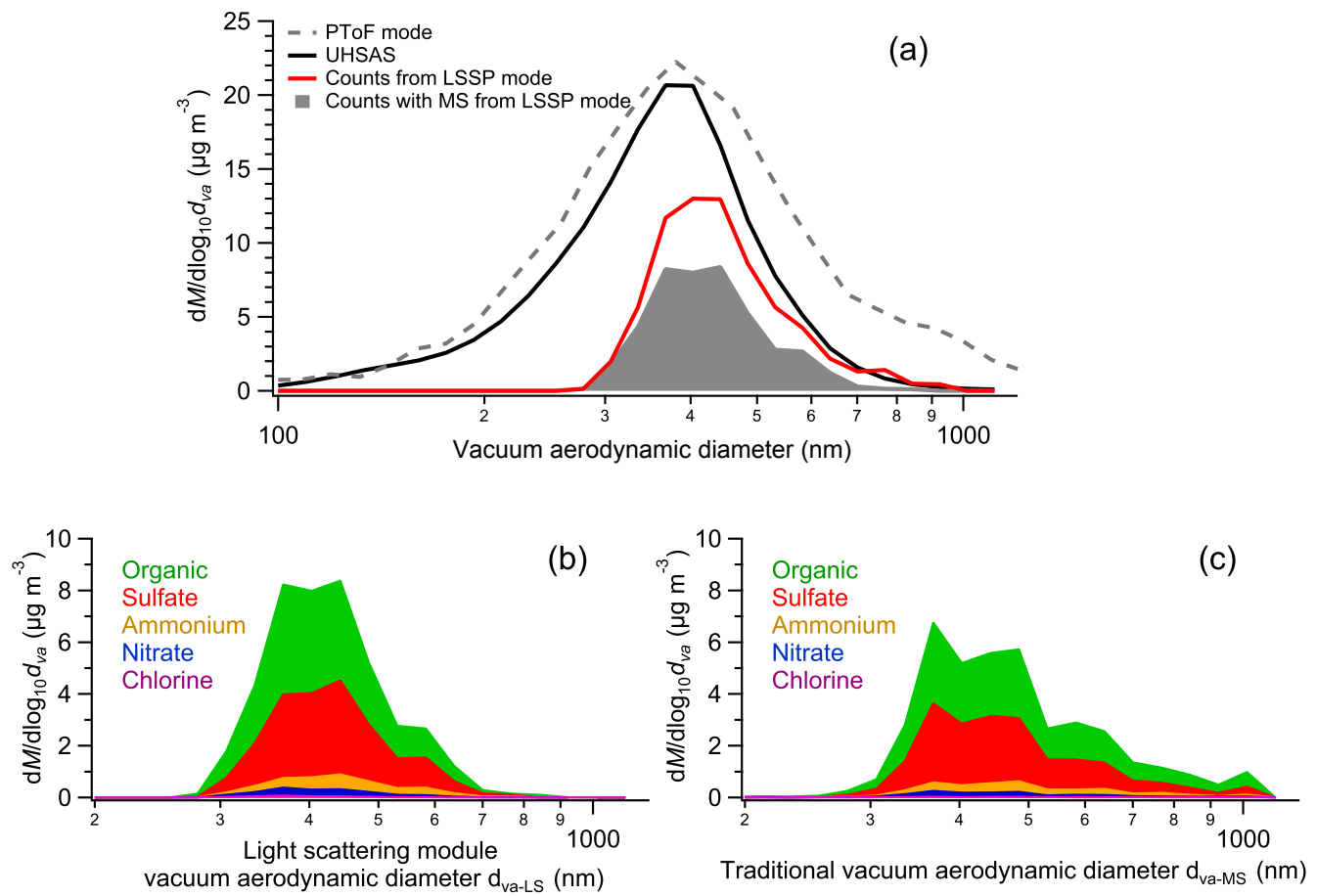

Figure 8. Size-dependent mass distributions as a function of vacuum aerodynamic diameter from low altitudes during the flight on

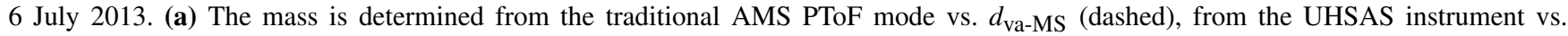
$d_{\mathrm{va}}$ (black) from Eq. (1) after correcting the particle number distribution for the AMS lens transmission and using an estimated density of $1.55 \mathrm{~g} \mathrm{~cm}^{-3}$, from the AMS LSSP internal particle counts vs. $d_{\mathrm{va}-\mathrm{LS}}$ (red) also using an estimated density of $1.55 \mathrm{~g} \mathrm{~cm}^{-3}$, and from the AMS LSSP counts with mass spectra (MS) vs. $d_{\mathrm{va}-\mathrm{LS}}$ (gray area). Panels (b) and (c) highlight the differences between plotting the mass distributions for each species measured using AMS LSSP mass spectra as a function of either (b) the light-scattering module derived vacuum aerodynamic diameter $\left(d_{\mathrm{va}-\mathrm{LS}}\right)$ or (c) the traditional vacuum aerodynamic diameter $\left(d_{\mathrm{va}-\mathrm{MS}}\right)$. All particles that scatter light and have mass spectra (including the delayed ones) are included in the $d_{\mathrm{va}-\mathrm{LS}}$ and $d_{\mathrm{va}-\mathrm{MS}}$ distributions (b, c). The difference between these two distributions arises because the size from light scattering $\left(d_{\mathrm{va}-\mathrm{LS}}\right)$ is more representative of the particle sizes, whereas $d_{\mathrm{va}-\mathrm{MS}}$ is influenced by particles that are delayed.

tional PToF mass distribution. The mass from the traditional PToF distribution (Fig. 8a, dashed curve) is higher than all the other curves for particles larger than $700 \mathrm{~nm}$ even considering the overall uncertainty. Compared to the distributions plotted as a function of $d_{\mathrm{va}-\mathrm{LS}}$, mass distributions as a function of $d_{\mathrm{va}-\mathrm{MS}}$ have less mass for the intermediate sizes $\left(d_{\mathrm{va}-\mathrm{MS}} \sim 350\right.$ to $\left.500 \mathrm{~nm}\right)$ and more mass at the larger sizes $\left(d_{\mathrm{va}-\mathrm{MS}}>700 \mathrm{~nm}\right)$.

On the small size of the mass distributions sizes $\left(d_{\mathrm{va}-\mathrm{LS}} \sim 100\right.$ to $\left.300 \mathrm{~nm}\right)$, there is additional mass measured in the PToF mode that does not appear in the LSSP data (Fig. 8a). This is not a bias in the PToF data at small sizes because it is also observed in the UHSAS data. These particles are too small for the scattered light signal to consistently trigger saving data in LSSP mode (see Fig. 2) and it is uncommon for particles to appear in the early part of the $8.3 \mathrm{~ms}$ long chopper cycle, even for particles such as pure ammonium sulfate that have a high tendency to bounce (Fig. 1). Furthermore, the PToF data are acquired by aggregating the bulk mass spectral signals over the sampling period rather than by aggregating single-particle mass spectral signals or indi- vidual particle counts from the laser. Thus, the PToF mode measures the mass from small particles which are not large enough to efficiently scatter light in the LSSP mode or generate enough ions for a clear signal from a single particle.

The broadening of the traditional AMS mass distribution to larger sizes due to delayed particles was also observed during the Mexico City and Bakersfield field studies (Cross et al., 2009; Liu et al., 2013) and the alpha-pinene SOA laboratory study (Robinson et al., 2017). Thus, $d_{\mathrm{va}-\mathrm{LS}}$ instead of $d_{\mathrm{va}-\mathrm{MS}}$ is a more reliable parameter to represent particle size in the AMS. On average, the relative composition as a function of size for the different distributions does not appear substantially different. The bias toward increased mass at the larger sizes from delayed particles needs to be considered when interpreting standard AMS PToF mass distribution data, especially if corrections to account for inlet transmission efficiency have been applied at large sizes. 


\subsubsection{Comparing the LSSP CE to the parameterized CE}

The light-scattering module can be used to measure in situ AMS CE, defined here as the ratio of number (or mass) of particles with both detectable chemical (prompt and delayed) and optical signals to the total number (or mass) of all particles with detectable optical signals. The numberbased CE from the LSSP data does not include counts from saved data where the scattered light signal was close to the noise level (optical detection limit) and is defined here as the (prompt + delayed) particle counts divided by (prompt + delayed + null) counts. The mass-based CE from LSSP data is defined in Sect. 3.2.2 as the ratio of the particle mass from the chemical ion signals (e.g., mass distribution shown as the gray area in Fig. 8a) to the particle mass from the laser counts (e.g., the area under the red curve in Fig. 8a).

Both number- and mass-based LSSP mode CE values for all the flights studied here are calculated for the $30 \mathrm{~s}$ intervals average of LSSP data every 5 min and are shown in Figs. 9a and S3. As mentioned before, because significant time was needed to save single-particle optical and chemical information, LSSP mode did not record all particles sampled. All of the CE measurements based on LSSP particle number or mass varied from about 0.2 to 0.9 for this study. The flight that had the largest range of CE, from about 0.4 to 0.9 based on the LSSP measurements, was on 6 July 2013 and is emphasized in Fig. 9.

The error bars on the number-based LSSP CE values in these figures (blue points) are the statistical variations of $\mathrm{CE}$ $\left(\sigma_{\mathrm{CE}}\right)$ for the LSSP data and are estimated to be less than \pm 0.08 for the $5 \mathrm{~min}$ average data based on variations of a binomial distribution as

$\sigma_{\mathrm{CE}}=\frac{\sqrt{n p(1-p)}}{n}$,

where $n$ is number of particles with optical signals above detection limit, and $p$ is the probability of optically detected particles that can be chemically detected, varying from 0.3 to 0.9. In addition to this statistical variability, the mass-based CE from the LSSP data has as much as $27 \%$ uncertainty from the measured particle volume from $9 \%$ uncertainty in $d_{\mathrm{va}-\mathrm{LS}}$. The error bars for the mass-based LSSP CE (yellow points in Figs. 9 and S3) were not included in the figures for clarity.

The large range of CE values for the flight on 6 July were clearly not due to statistical variation. For this flight, the ratio of MS mode ammonium to predicted ammonium from full neutralization of sulfate plus nitrate varied more than for all of the other flights, indicating that the aerosol on this flight was at times significantly more acidic on average than for other flights. The relative humidity for this particular flight was also a bit higher on average than the other flights. Thus, the acidity and relative humidity likely had an influence on the $\mathrm{CE}$ for this flight more than on the other flights.
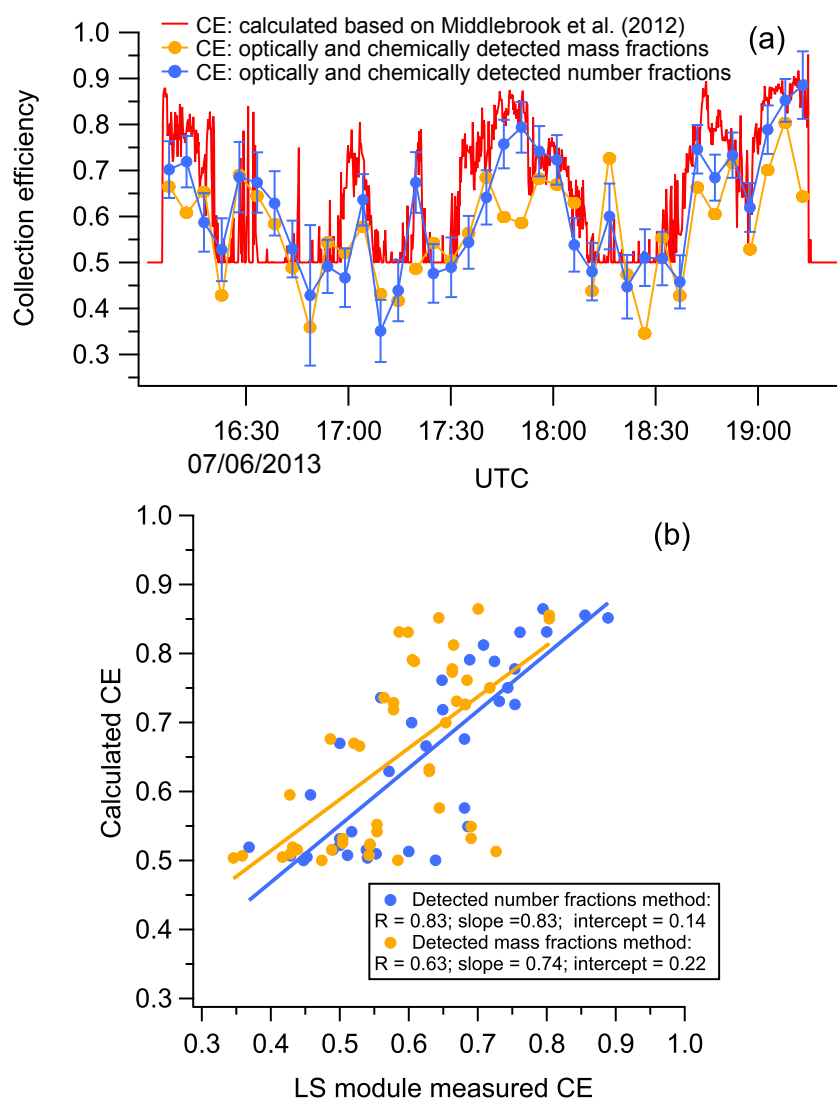

Figure 9. (a) Time series plot of AMS collection efficiency calculated based on aerosol chemical composition and relative humidity method described in Middlebrook et al. (2012) (red) and measured by AMS LSSP mode based on number (blue) or mass (yellow) ratio of optically and chemically detected particles to total optically detected particles of 6 July 2013 flight. (b) Scatter plot of the parameterized, composition-dependent CE vs. the LS module measured CE based on optically and chemically detected particle number fractions (blue, correlation coefficient $R=0.82$ ) and mass fractions (yellow, correlation coefficient $R=0.64$ ) for the 6 July 2013 flight.

The parameterization of CE based on the bulk MS mode composition data incorporates variations in $\mathrm{CE}$ due to acidity and sampling line relative humidity (Middlebrook et al., 2012) and is commonly used in AMS data analysis software. In contrast to CE measurements from LSSP mode data, the CE parameterization covers the entire particle size range detected in MS or PToF mode (Fig. 8a). Since the bulk MS mode data are saved every $10 \mathrm{~s}$, the parameterized CE is calculated for that time interval and is shown in Figs. 9 and S3 as red lines connecting points.

There are many factors influencing the point-by-point $\mathrm{CE}$ comparison shown in Fig. 9b and all three types of CE determinations have limitations. The CE parameterization has about $20 \%$ uncertainty (based on Middlebrook et al., 2012) and could contribute to the noise in the red traces of Figs. 9a 
and S3. In addition, there are statistical variations on the LSSP-based CEs as described above. Also we did not parse the data sets for low statistics from either low LS particle counts or low total bulk mass, which is approximately only an issue for the high-altitude data points. LSSP and MS data were not obtained at the same time and the air masses sampled could be changing rapidly since the aircraft is moving about $100 \mathrm{~m} \mathrm{~s}^{-1}$, such that each CE data point from the parameterization is about $1 \mathrm{~km}$ apart, each LSSP CE data point represents a $3 \mathrm{~km}$ average, and each LSSP CE data point is $30 \mathrm{~km}$ apart. Two-minute averages of the CEs from the parameterization were used to generate the comparison plot in Fig. 9b. For this flight on 6 July, the (observed or calculated) range in $\mathrm{CE}$ is much larger on average than for the other flights and varied on larger temporal (spatial) scales, and the CE variability was outside of the combined error bars.

Given all of these uncertainties, the three values for $\mathrm{CE}$ shown in Fig. 9 were correlated and generally agreed well. CE values above 0.5 were primarily due to the presence of acidic sulfate particles during this flight and were determined by both composition-dependent $\mathrm{CE}$ parameterization from the ensemble MS mode data and in situ LSSP mode measurements. The good correlation indicates that the aerosol chemical composition and relative-humidity-dependent $\mathrm{CE}$ parameterization (Middlebrook et al., 2012) can accurately capture the general variability of LSSP-based CEs at least for the cases when significant variation in $\mathrm{CE}$ is due to change of aerosol acidity.

The default CE parameterization value of 0.5 may be too high during some parts of this flight and large parts of other flights (Fig. S3). This was also observed with other field data using a mass-based comparison to evaluated CE (Middlebrook et al., 2012) and may indicate that the default CE of 0.5 is slightly high in the parameterization. One flight in particular (3 July) had the highest null fractions (Fig. 3) and corresponding lower CEs for most of the flight compared to other flights. This flight had an overall higher mass loading of $\mathrm{rBC}$ from biomass burning in the sampled air $(0.36 \mu \mathrm{g}$ $\mathrm{sm}^{-3}$, whereas the average for all of the flights analyzed here was $0.14 \mu \mathrm{g} \mathrm{sm}^{-3}$ ). If an individual particle is mostly $\mathrm{rBC}$, there may not be enough ion signal from the nonrefractory components to detect it with the mass spectrometer. In Toronto, a higher null fraction was measured when urban, rBC-containing particles were evaporated with a vaporizer instead of an infrared laser (Lee et al., 2015). It is also possible that the $\mathrm{CE}$ is lower for the organic fraction of biomass burning aerosols. The effect of biomass burning particles on the measured CE with the LS-AMS needs further investigation.

\subsubsection{Additional considerations for the LSSP-based collection efficiencies}

CE is traditionally defined based on mass comparisons. There is an assumption in applying either a calculated or an in situ CE to the measured mass loadings from MS mode that the chemical composition of the undetected mass is the same as the detected mass, which is likely true during sampling of air masses with mostly mixed secondary aerosol particles. In general for SENEX, the number- and mass-based CE from the LSSP data shown in Fig. 9 and Fig. S3 are comparable within experimental uncertainties for the particles sampled. In Fig. 8a, the integrated mass from the PToF mass distribution using the average $\mathrm{CE}$ from the parameterization of 0.6 for the flight on 6 July (dashed curve) is also within the combined experimental uncertainties of the integrated mass from the UHSAS mass distribution (solid black curve). The flightaveraged number-based CE was 0.58. Hence, the SENEX field data did not show any large discrepancies between the number- and mass-based CEs when averaged for the entire flight.

It is also assumed that particles detected optically are representative of all particles sampled by the AMS and have the same chemical composition as the particles that are too small to be detected by LSSP mode. In air masses where newly formed and growing (Aitken mode) particles are present, this assumption is not necessarily valid. The number- and mass-based CEs may be different if there are significant differences in the number-based $\mathrm{CE}$ as a function of size, as briefly described by Huffman et al. (2005). In power plant plumes that were sampled by the PToF mode during SENEX, we sometimes observed smaller acidic sulfate particles with larger mixed composition particles. Because these power plant plumes were transected quickly by the aircraft, the small particles were not sampled consistently with LSSP mode, and so the effect of a varying composition with size could not be evaluated here.

For comparison, mass-based and number-based CEs have been reported from other studies. The Bakersfield study described a discrepancy between the average number- and mass-based CEs, where the number-based value was $\sim 0.5$ and the mass-based value from ensemble measurements was 0.8 (Liu et al., 2013). The authors proposed that a mismatch of vaporization and data acquisition timescales reduced the detected chemical ion signals from single particles compared to the ensemble measurements; however, this discrepancy was not resolved. The in situ CE from LSSP mode measurements were also determined and compared with AMS ensemble and independent measurements for the Mexico City study (Cross et al., 2009). The number- and mass-based CE was on average $\sim 0.5$ for the $75 \mathrm{~h}$ sampling period of LSSP data and showed some size dependence with the smallest particles having a high $\mathrm{CE}$ (low null fraction and higher prompt fraction) than the larger particles.

While the aircraft data reported here show a wide range of CE due to air mass variations, such variability in the LSSP mode $\mathrm{CE}$ has not been reported previously. Variations in ensemble CE were not reported in the previous ambient studies but could have been possible due to the diurnal variability in the ambient measurements from Mexico City, where in the 
morning there were small particles composed of predominantly hydrocarbon-like organic aerosol, which appeared to have a higher CE (Cross et al., 2009). Hence, LSSP data could also show that mixing state plays a role in the measured CE.

\section{Conclusions}

This paper reports airborne single-particle measurements from a light-scattering module coupled to an AMS instrument and uses these measurements to investigate the CE obtained in situ for ambient particles. Results from these unique airborne single-particle measurements showed that the LS module has the capability to measure in situ AMS CE despite many assumptions and uncertainties in this method. The comparison of measured and calculated CE demonstrated that the aerosol chemical composition and humiditydependent CE parameterization that is commonly used to process AMS data is reasonable for the cases when aerosol acidity plays a role in ambient CE variations. Single-particle data derived average aerosol chemical composition fractions were generally well correlated with the ensemble data. This shows that the airborne AMS with an LS module is a potentially useful tool for measuring the ambient aerosol chemical composition. However, the effectiveness of the LSSP mode for ambient measurements is limited to particles that are large enough to scatter light and generate sufficient chemical ion signals to be detected. As shown in Fig. 8a, LSSP mode clearly cannot measure a large fraction of the ambient aerosol mass distribution. Furthermore, the duty cycle is quite high for LSSP mode, reducing the number of particles recorded and needing information from the adjacent MS modes to normalize LSSP data. The MS detection limit is also important for the new event-trigger AMS mode, which saves individual particle spectra from a single chopper cycle when the mass spectral signals of selected ions are above a threshold.

The different chemical ion signals in prompt and delayed particles indicated that delayed particles are likely those that bounce off the vaporizer surface and vaporize at a lower temperature after impacting another surface. The field measurements and laboratory data both demonstrate that the mass spectra from delayed particles have less fragmentation and slightly lower chemical ion signals than spectra from prompt particles. The individual particle mass appears to be consistent with most of the material vaporizing for both prompt and delayed ambient particles from SENEX and there is only about a $20 \%$ decrease in the number of ions produced from delayed particles compared to prompt particles despite differences in their mass spectra. Delayed particles appear as larger particles in the traditional AMS PToF mass distribution. Caution should therefore be used when interpreting AMS PToF mode particle size data when delayed particles occur.
Data availability. Data are partially available from the CSD NOAA data archive, https://esrl.noaa.gov/csd/groups/csd7/ measurements/2013senex/P3/DataDownload/ (NOAA, 2017). Additional data can be obtained from the authors upon request (ann.m.middlebrook@noaa.gov).

\section{The Supplement related to this article is available online} at https://doi.org/10.5194/amt-10-3801-2017-supplement.

Competing interests. Donna T. Sueper is an employee of Aerodyne, which sells the AMS. The other authors declare no competing interests.

Acknowledgements. We thank Joel Kimmel, Tim Onasch, Steven Brown, and Annie Davis for their help to tune the AMS instrument, troubleshoot light-scattering module, align the laser, and plot Fig. S1, respectively. Discussions of pre-publication results with Ellis Robinson, Neal Donahue, Jose Jimenez, and Weiwei Hu were important to the interpretation of our field data. We also thank the NOAA CSD black carbon group for their measurements during SENEX.

Edited by: Gavin Phillips

Reviewed by: two anonymous referees

\section{References}

Allan, J. D., Delia, A. E., Coe, H., Bower, K. N., Alfarra, M. R., Jimenez, J. L., Middlebrook, A. M., Drewnick, F., Onasch, T. B., Canagaratna, M. R., Jayne, J. T., and Worsnop, D. R.: A generalised method for the extraction of chemically resolved mass spectra from Aerodyne aerosol mass spectrometer data, J. Aerosol Sci., 35, 909-922, https://doi.org/10.1016/j.jaerosci.2004.02.007, 2004.

Bahreini, R., Dunlea, E. J., Matthew, B. M., Simons, C., Docherty, K. S., DeCarlo, P. F., Jimenez, J. L., Brock, C. A., and Middlebrook, A. M.: Design and operation of a pressurecontrolled inlet for airborne sampling with an aerodynamic aerosol lens, Aerosol Sci. Tech., 42, 465-471, https://doi.org/10.1080/02786820802178514, 2008.

Bahreini, R., Ervens, B., Middlebrook, A. M., Warneke, C., de Gouw, J. A., DeCarlo, P. F., Jimenez, J. L., Brock, C. A., Neuman, J. A., Ryerson, T. B., Stark, H., Atlas, E., Brioude, J., Fried, A., Holloway, J. S., Peischl, J., Richter, D., Walega, J., Weibring, P., Wollny, A. G., and Fehsenfeld, F. C.: Organic aerosol formation in urban and industrial plumes near Houston and Dallas, Texas, J. Geophys. Res.-Atmos., 114, D00F16, https://doi.org/10.1029/2008JD011493, 2009.

Brock, C. A., Wagner, N. L., Anderson, B. E., Attwood, A. R., Beyersdorf, A., Campuzano-Jost, P., Carlton, A. G., Day, D. A., Diskin, G. S., Gordon, T. D., Jimenez, J. L., Lack, D. A., Liao, J., Markovic, M. Z., Middlebrook, A. M., Ng, N. L., Perring, A. E., Richardson, M. S., Schwarz, J. P., Washenfelder, R. A., 
Welti, A., Xu, L., Ziemba, L. D., and Murphy, D. M.: Aerosol optical properties in the southeastern United States in summer - Part 1: Hygroscopic growth, Atmos. Chem. Phys., 16, 49875007, https://doi.org/10.5194/acp-16-4987-2016, 2016.

Canagaratna, M. R., Jayne, J. T., Jimenez, J. L., Allan, J. D., Alfarra, M. R., Zhang, Q., Onasch, T. B., Drewnick, F., Coe, H., Middlebrook, A., Delia, A., Williams, L. R., Trimborn, A. M., Northway, M. J., DeCarlo, P. F., Kolb, C. E., Davidovits, P., and Worsnop, D. R.: Chemical and microphysical characterization of ambient aerosols with the aerodyne aerosol mass spectrometer, Mass Spectrom. Rev., 26, 185-222, https://doi.org/10.1002/mas.20115, 2007.

Canagaratna, M. R., Massoli, P., Browne, E. C., Franklin, J. P., Wilson, K. R., Onasch, T. B., Kirchstetter, T. W., Fortner, E. C., Kolb, C. E., Jayne, J. T., Kroll, J. H., and Worsnop, D. R.: Chemical compositions of black carbon particle cores and coatings via soot particle aerosol mass spectrometry with photoionization and electron ionization, J. Phys. Chem. A, 119, 4589-4599, https://doi.org/10.1021/jp510711u, 2015.

Cross, E. S., Slowik, J. G., Davidovits, P., Allan, J. D., Worsnop, D. R., Jayne, J. T., Lewis, D. K., Canagaratna, M., and Onasch, T. B.: Laboratory and ambient particle density determinations using light scattering in conjunction with aerosol mass spectrometry, Aerosol Sci. Tech., 41, 343-359, https://doi.org/10.1080/02786820701199736, 2007.

Cross, E. S., Onasch, T. B., Canagaratna, M., Jayne, J. T., Kimmel, J., Yu, X.-Y., Alexander, M. L., Worsnop, D. R., and Davidovits, P.: Single particle characterization using a light scattering module coupled to a time-of-flight aerosol mass spectrometer, Atmos. Chem. Phys., 9, 7769-7793, https://doi.org/10.5194/acp-9-77692009, 2009.

Day, D. A., Flagan, R. C., Worsnop, D. R., and Jimenez, J. L.: Size resolution of the Aerodyne aerosol mass spectrometer, American Association for Aerosol Research 30th Annual Conference, 3-7 October 2011, Orlando, Florida, USA, 5 A.21, 2011.

DeCarlo, P. F., Slowik, J. G., Worsnop, D. R., Davidovits, P., and Jimenez, J. L.: Particle morphology and density characterization by combined mobility and aerodynamic diameter measurements. Part I: Theory, Aerosol Sci. Tech., 38, 1185-1205, https://doi.org/10.1080/027868290903907, 2004.

Drewnick, F., Hings, S. S., DeCarlo, P., Jayne, J. T., Gonin, M., Fuhrer, K., Weimer, S., Jimenez, J. L., Demerjian, K. L., Borrmann, S., and Worsnop, D. R.: A new time-of-flight aerosol mass spectrometer (TOF-AMS) - instrument description and first field deployment, Aerosol Sci. Tech., 39, 637-658, https://doi.org/10.1080/02786820500182040, 2005.

Drewnick, F., Diesch, J.-M., Faber, P., and Borrmann, S.: Aerosol mass spectrometry: particle-vaporizer interactions and their consequences for the measurements, Atmos. Meas. Tech., 8, 38113830, https://doi.org/10.5194/amt-8-3811-2015, 2015.

Freutel, F., Drewnick, F., Schneider, J., Klimach, T., and Borrmann, S.: Quantitative single-particle analysis with the Aerodyne aerosol mass spectrometer: development of a new classification algorithm and its application to field data, Atmos. Meas. Tech., 6, 3131-3145, https://doi.org/10.5194/amt-6-3131-2013, 2013.

Hennigan, C. J., Izumi, J., Sullivan, A. P., Weber, R. J., and Nenes, A.: A critical evaluation of proxy methods used to estimate the acidity of atmospheric particles, Atmos. Chem. Phys., 15, 27752790, https://doi.org/10.5194/acp-15-2775-2015, 2015.

Hings, S. S., Walter, S., Schneider, J., Borrmann, S., and Drewnick, F.: Comparison of a quadrupole and a time-of-flight aerosol mass spectrometer during the Feldberg aerosol characterization experiment 2004, Aerosol Sci. Tech., 41, 679-691, https://doi.org/10.1080/02786820701408483, 2007.

Hu, W., Campuzano-Jost, P., Day, D. A., Croteau, P., Canagaratna, M. R., Jayne, J. T., Worsnop, D. R., and Jimenez, J. L.: Evaluation of the new capture vapourizer for aerosol mass spectrometers (AMS) through laboratory studies of inorganic species, Atmos. Meas. Tech., 10, 2897-2921, https://doi.org/10.5194/amt10-2897-2017, 2017.

Huffman, J. A., Jayne, J. T., Drewnick, F., Aiken, A. C., Onasch, T., Worsnop, D. R., and Jimenez, J. L.: Design, modeling, optimization, and experimental tests of a particle beam width probe for the aerodyne aerosol mass spectrometer, Aerosol Sci. Tech., 39, 1143-1163, https://doi.org/10.1080/02786820500423782, 2005.

Jayne, J. T., Leard, D. C., Zhang, X. F., Davidovits, P., Smith, K. A., Kolb, C. E., and Worsnop, D. R.: Development of an aerosol mass spectrometer for size and composition analysis of submicron particles, Aerosol Sci. Tech., 33, 49-70, https://doi.org/10.1080/027868200410840, 2000.

Jimenez, J. L., Canagaratna, M. R., Donahue, N. M., Prevot, A. S. H., Zhang, Q., Kroll, J. H., DeCarlo, P. F., Allan, J. D., Coe, H., Ng, N. L., Aiken, A. C., Docherty, K. S., Ulbrich, I. M., Grieshop, A. P., Robinson, A. L., Duplissy, J., Smith, J. D., Wilson, K. R., Lanz, V. A., Hueglin, C., Sun, Y. L., Tian, J., Laaksonen, A., Raatikainen, T., Rautiainen, J., Vaattovaara, P., Ehn, M., Kulmala, M., Tomlinson, J. M., Collins, D. R., Cubison, M. J., Dunlea, E. J., Huffman, J. A., Onasch, T. B., Alfarra, M. R., Williams, P. I., Bower, K., Kondo, Y., Schneider, J., Drewnick, F., Borrmann, S., Weimer, S., Demerjian, K., Salcedo, D., Cottrell, L., Griffin, R., Takami, A., Miyoshi, T., Hatakeyama, S., Shimono, A., Sun, J. Y., Zhang, Y. M., Dzepina, K., Kimmel, J. R., Sueper, D., Jayne, J. T., Herndon, S. C., Trimborn, A. M., Williams, L. R., Wood, E. C., Middlebrook, A. M., Kolb, C. E., Baltensperger, U., and Worsnop, D. R.: Evolution of organic aerosols in the atmosphere, Science, 326, 1525-1529, https://doi.org/10.1126/science.1180353, 2009.

Jimenez, J. L., Jayne, J. T., Shi, Q., Kolb, C. E., Worsnop, D. R., Yourshaw, I., Seinfeld, J. H., Flagan, R. C., Zhang, X. F., Smith, K. A., Morris, J. W., and Davidovits, P.: Ambient aerosol sampling using the Aerodyne Aerosol Mass Spectrometer, J. Geophys. Res.-Atmos., 108, 8425, https://doi.org/10.1029/2001jd001213, 2003.

Kiendler-Scharr, A., Zhang, Q., Hohaus, T., Kleist, E., Mensah, A., Mentel, T. F., Spindler, C., Uerlings, R., Tillmann, R., and Wildt, J.: Aerosol mass spectrometric features of biogenic SOA: observations from a plant chamber and in rural atmospheric environments, Environ. Sci. Technol., 43, 8166-8172, https://doi.org/10.1021/es901420b, 2009.

Lee, A. K. Y., Willis, M. D., Healy, R. M., Onasch, T. B., and Abbatt, J. P. D.: Mixing state of carbonaceous aerosol in an urban environment: single particle characterization using the soot particle aerosol mass spectrometer (SP-AMS), Atmos. Chem. Phys., 15, 1823-1841, https://doi.org/10.5194/acp15-1823-2015, 2015. 
Levin, E. J. T., Prenni, A. J., Palm, B. B., Day, D. A., Campuzano-Jost, P., Winkler, P. M., Kreidenweis, S. M., DeMott, P. J., Jimenez, J. L., and Smith, J. N.: Size-resolved aerosol composition and its link to hygroscopicity at a forested site in Colorado, Atmos. Chem. Phys., 14, 2657-2667, https://doi.org/10.5194/acp-14-2657-2014, 2014.

Liu, P. S. K., Deng, R., Smith, K. A., Williams, L. R., Jayne, J. T., Canagaratna, M. R., Moore, K., Onasch, T. B., Worsnop, D. R., and Deshler, T.: Transmission efficiency of an aerodynamic focusing lens system: comparison of model calculations and laboratory measurements for the Aerodyne aerosol mass spectrometer, Aerosol Sci. Tech., 41, 721-733, https://doi.org/10.1080/02786820701422278, 2007.

Liu, S., Russell, L. M., Sueper, D. T., and Onasch, T. B.: Organic particle types by single-particle measurements using a time-of-flight aerosol mass spectrometer coupled with a light scattering module, Atmos. Meas. Tech., 6, 187-197, https://doi.org/10.5194/amt-6-187-2013, 2013.

Matthew, B. M., Middlebrook, A. M., and Onasch, T. B.: Collection efficiencies in an Aerodyne Aerosol Mass Spectrometer as a function of particle phase for laboratory generated aerosols, Aerosol Sci. Tech., 42, 884-898, https://doi.org/10.1080/02786820802356797, 2008.

Middlebrook, A. M., Bahreini, R., Jimenez, J. L., and Canagaratna, M. R.: Evaluation of composition-dependent collection efficiencies for the aerodyne aerosol mass spectrometer using field data, Aerosol Sci. Tech., 46, 258-271, https://doi.org/10.1080/02786826.2011.620041, 2012.

Miyakawa, T., Matsuzawa, R., Katayama, M., and Takegawa, N.: Reconsidering adhesion and bounce of submicron particles upon high-velocity impact, Aerosol Sci. Tech., 47, 472-481, https://doi.org/10.1080/02786826.2013.763895, 2013.

National Oceanic and Atmospheric Administration (NOAA): SENEX 2013 CSD Data Archive, Earth System Research Laboratory, Chemical Sciences Division, available at: https://esrl.noaa.gov/csd/groups/csd7/measurements/2013senex/ P3/DataDownload/, last access: 13 October 2017.

Öztürk, F., Bahreini, R., Wagner, N. L., Dubé, W. P., Young, C. J., Brown, S. S., Brock, C. A., Ulbrich, I. M., Jimenez, J. L., Cooper, O. R., and Middlebrook, A. M.: Vertically resolved chemical characteristics and sources of submicron aerosols measured on a Tall Tower in a suburban area near Denver, Colorado in winter, J. Geophys. Res.-Atmos., 118, 13591-13605, https://doi.org/10.1002/2013JD019923, 2013.

Perry, R. H. and Green, D. W. (Eds.): Perry's Chemical Engineers' Handbook, Table 2-37, McGraw-Hill, New York, NY, USA, 1997.

Ramanathan, V., Crutzen, P. J., Kiehl, J. T., and Rosenfeld, D.: Aerosols, climate, and the hydrological cycle, Science, 294, 2119-2124, https://doi.org/10.1126/science.1064034, 2001.

Retama, A., Baumgardner, D., Raga, G. B., McMeeking, G. R., and Walker, J. W.: Seasonal and diurnal trends in black carbon properties and co-pollutants in Mexico City, Atmos. Chem. Phys., 15, 9693-9709, https://doi.org/10.5194/acp-15-9693-2015, 2015.

Robinson, E. S., Saleh, R., and Donahue, N. M.: Organic aerosol mixing observed by single-particle mass spectrometry, J. Phys. Chem. A, 117, 13935-13945, https://doi.org/10.1021/jp405789t, 2013.
Robinson, E. S., Onasch, T. B., Worsnop, D., and Donahue, N. M.: Collection efficiency of $\alpha$-pinene secondary organic aerosol particles explored via light-scattering single-particle aerosol mass spectrometry, Atmos. Meas. Tech., 10, 1139-1154, https://doi.org/10.5194/amt-10-1139-2017, 2017.

Slowik, J. G., Stroud, C., Bottenheim, J. W., Brickell, P. C., Chang, R. Y.-W., Liggio, J., Makar, P. A., Martin, R. V., Moran, M. D., Shantz, N. C., Sjostedt, S. J., van Donkelaar, A., Vlasenko, A., Wiebe, H. A., Xia, A. G., Zhang, J., Leaitch, W. R., and Abbatt, J. P. D.: Characterization of a large biogenic secondary organic aerosol event from eastern Canadian forests, Atmos. Chem. Phys., 10, 2825-2845, https://doi.org/10.5194/acp-102825-2010, 2010.

Takegawa, N., Miyazaki, Y., Kondo, Y., Komazaki, Y., Miyakawa, T., Jimenez, J. L., Jayne, J. T., Worsnop, D. R., Allan, J. D., and Weber, R. J.: Characterization of an Aerodyne Aerosol Mass Spectrometer (AMS): intercomparison with other aerosol instruments, Aerosol Sci. Tech., 39, 760-770, https://doi.org/10.1080/02786820500243404, 2005.

Warneke, C., Trainer, M., de Gouw, J. A., Parrish, D. D., Fahey, D. W., Ravishankara, A. R., Middlebrook, A. M., Brock, C. A., Roberts, J. M., Brown, S. S., Neuman, J. A., Lerner, B. M., Lack, D., Law, D., Hübler, G., Pollack, I., Sjostedt, S., Ryerson, T. B., Gilman, J. B., Liao, J., Holloway, J., Peischl, J., Nowak, J. B., Aikin, K. C., Min, K.-E., Washenfelder, R. A., Graus, M. G., Richardson, M., Markovic, M. Z., Wagner, N. L., Welti, A., Veres, P. R., Edwards, P., Schwarz, J. P., Gordon, T., Dube, W. P., McKeen, S. A., Brioude, J., Ahmadov, R., Bougiatioti, A., Lin, J. J., Nenes, A., Wolfe, G. M., Hanisco, T. F., Lee, B. H., LopezHilfiker, F. D., Thornton, J. A., Keutsch, F. N., Kaiser, J., Mao, J., and Hatch, C. D.: Instrumentation and measurement strategy for the NOAA SENEX aircraft campaign as part of the Southeast Atmosphere Study 2013, Atmos. Meas. Tech., 9, 3063-3093, https://doi.org/10.5194/amt-9-3063-2016, 2016.

Zelenyuk, A., Imre, D., Han, J. H., and Oatis, S.: Simultaneous measurements of individual ambient particle size, composition, effective density, and hygroscopicity, Anal. Chem., 80, 1401-1407, https://doi.org/10.1021/ac701723v, 2008.

Zhang, Q., Jimenez, J. L., Canagaratna, M. R., Allan, J. D., Coe, H., Ulbrich, I., Alfarra, M. R., Takami, A., Middlebrook, A. M., Sun, Y. L., Dzepina, K., Dunlea, E., Docherty, K., DeCarlo, P. F., Salcedo, D., Onasch, T., Jayne, J. T., Miyoshi, T., Shimono, A., Hatakeyama, S., Takegawa, N., Kondo, Y., Schneider, J., Drewnick, F., Borrmann, S., Weimer, S., Demerjian, K., Williams, P., Bower, K., Bahreini, R., Cottrell, L., Griffin, R. J., Rautiainen, J., Sun, J. Y., Zhang, Y. M., and Worsnop, D. R.: Ubiquity and dominance of oxygenated species in organic aerosols in anthropogenically-influenced Northern Hemisphere midlatitudes, Geophys. Res. Lett., 34, L13801, https://doi.org/10.1029/2007gl029979, 2007a.

Zhang, Q., Jimenez, J. L., Worsnop, D. R., and Canagaratna, M.: A case study of urban particle acidity and its influence on secondary organic aerosol, Environ. Sci. Technol., 41, 3213-3219, https://doi.org/10.1021/es061812j, 2007b. 